\title{
Wyoming Greater Sage-grouse Habitat Prioritization: A Collection of Multi-scale Seasonal Models and Geographic Information System Land Management Tools
}

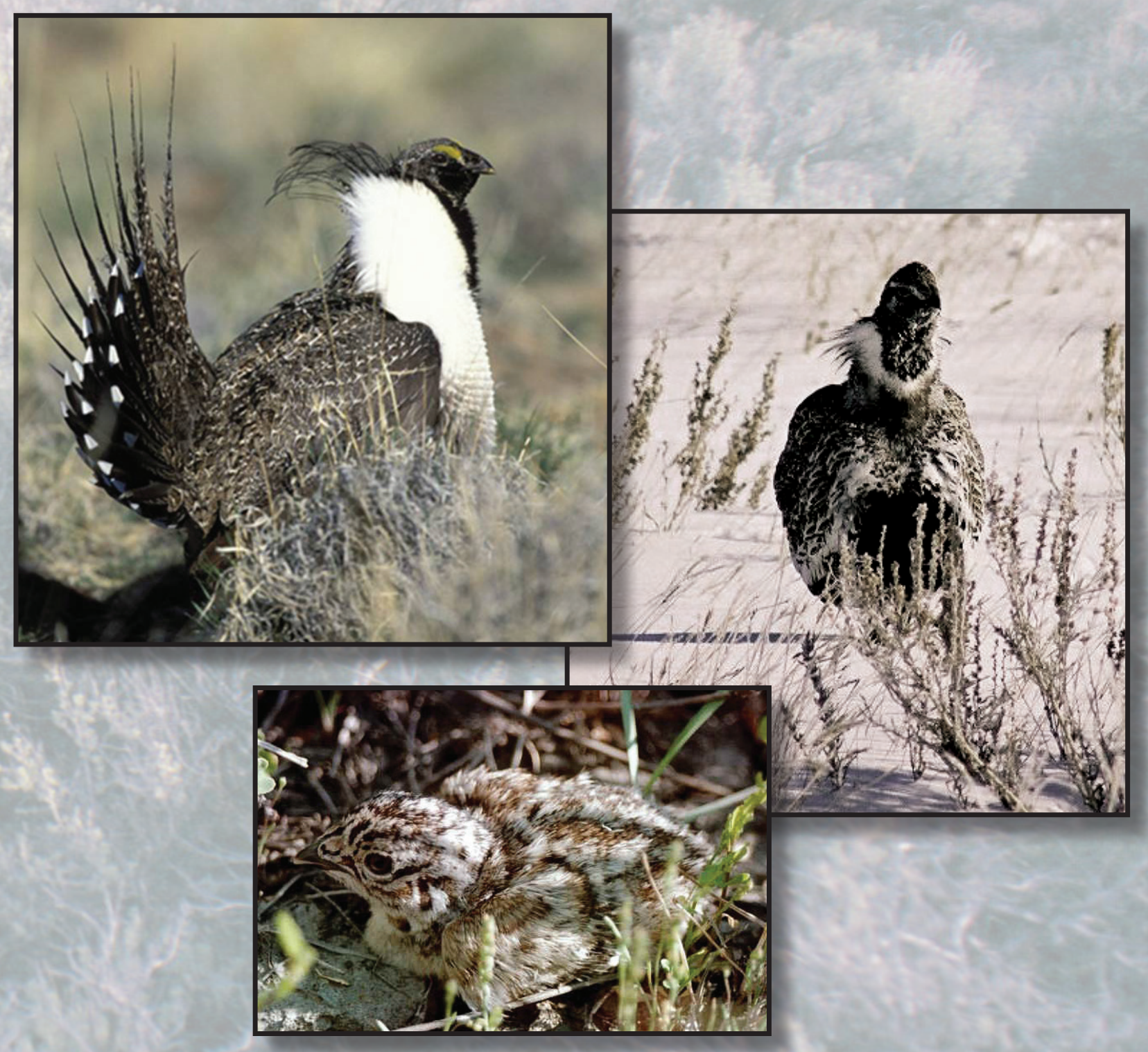

Data Series 891

U.S. Department of the Interior U.S. Geological Survey 


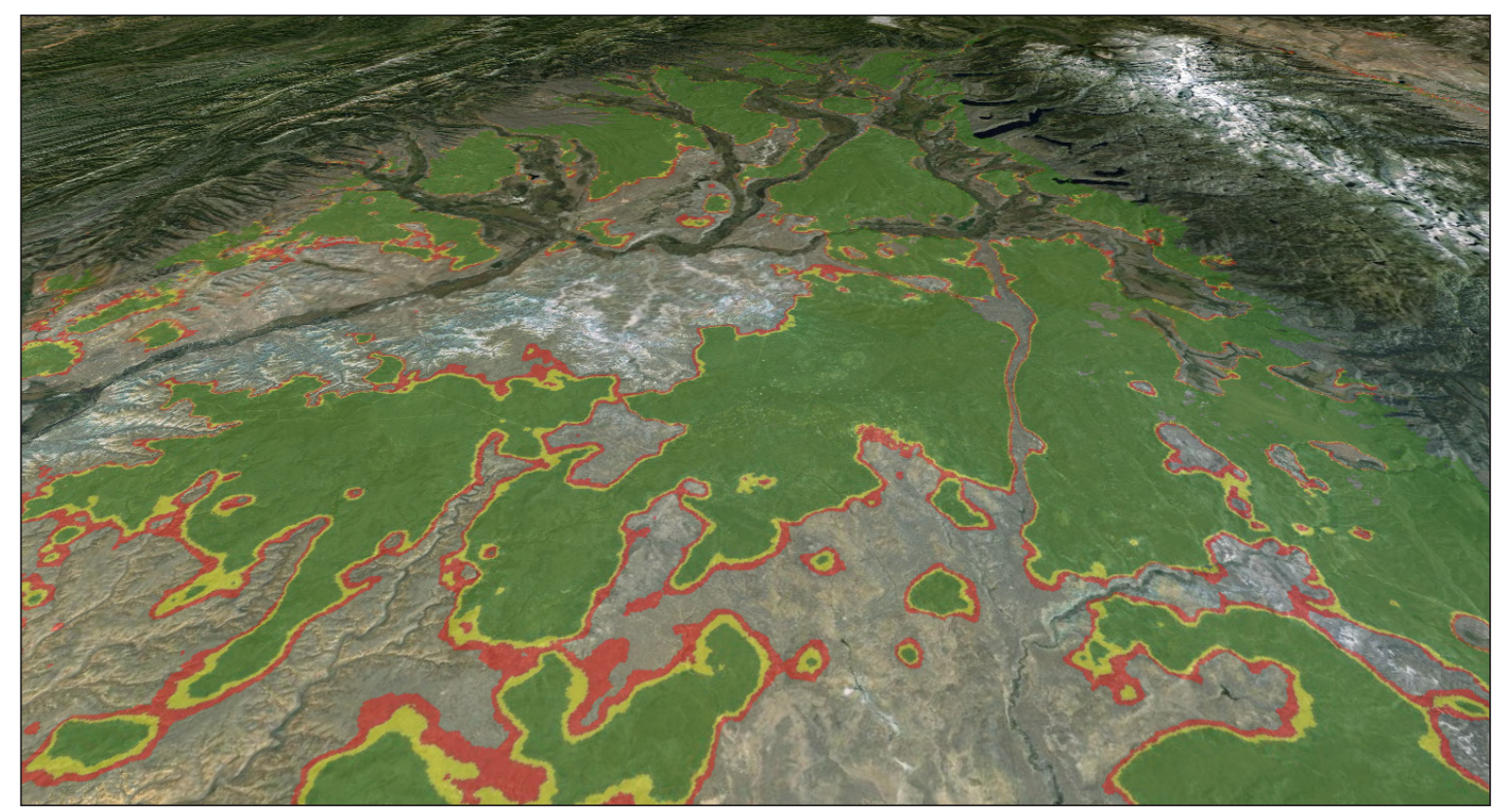

Aerial map of Greater Sage-grouse nesting habitat model (created by Michael O'Donnell).

Cover: Background: Sagebush panoramic. Photograph taken and copyrighted by Cameron Aldridge (2006). Top left: Greater Sage grouse. Photograph by Gary Kramer, U.S. Fish and Wildlife Service. Bottom left: Greater Sage grouse. Photograph taken and copyrighted by Cameron Aldridge (2006). Center right: Greater Sage grouse. Photograph taken and copyrighted by Michael Swystun (2005). 


\section{Wyoming Greater Sage-grouse Habitat Prioritization: A Collection of Multi-scale Seasonal Models and Geographic Information System Land Management Tools}

By Michael S. O'Donnell, Cameron L. Aldridge, Kevin E. Doherty, and Bradley C. Fedy

Data Series 891 


\title{
U.S. Department of the Interior SALLY JEWELL, Secretary
}

\section{U.S. Geological Survey \\ Suzette M. Kimball, Acting Director}

\author{
U.S. Geological Survey, Reston, Virginia: 2015
}

For more information on the USGS - the Federal source for science about the Earth, its natural and living resources, natural hazards, and the environment, visit http://www.usgs.gov or call 1-888-ASK-USGS.

For an overview of USGS information products, including maps, imagery, and publications, visit http://www.usgs.gov/pubprod

To order this and other USGS information products, visit http://store.usgs.gov

Any use of trade, firm, or product names is for descriptive purposes only and does not imply endorsement by the U.S. Government.

Although this information product, for the most part, is in the public domain, it also may contain copyrighted materials as noted in the text. Permission to reproduce copyrighted items must be secured from the copyright owner.

Suggested citation:

O'Donnell, M.S., Aldridge, C.L., Doherty, K.E., and Fedy, B.C., 2015, Wyoming greater sage-grouse habitat prioritizationA collection of multi-scale seasonal models and geographic information systems land management tools: U.S. Geological Survey Data Series 891, 28 p., http://dx.doi.org/10.3133/ds891.

ISSN 2327-638X (online) 


\section{Contents}

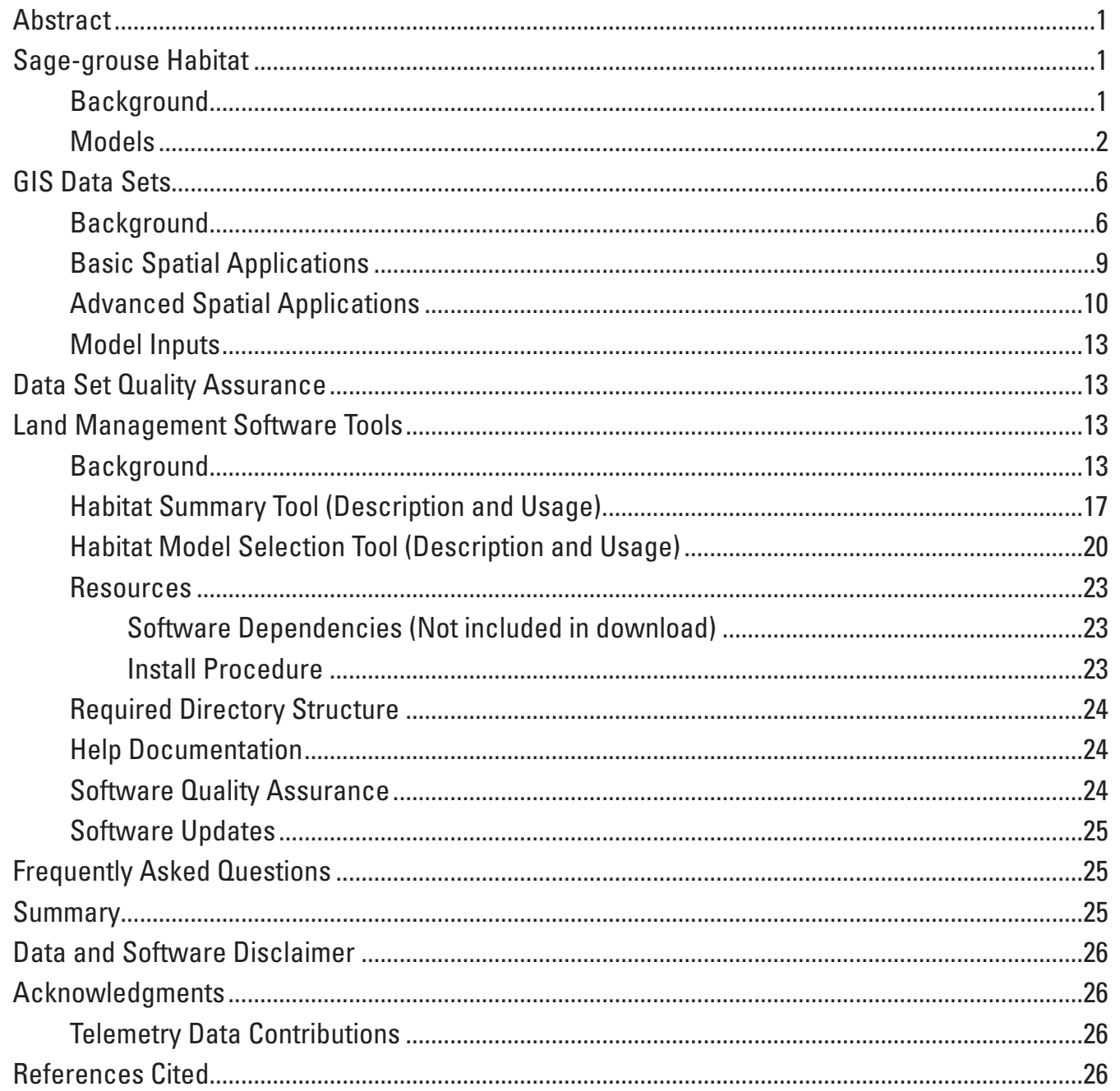

\section{Figures}

1. Regional boundary identification for sage-grouse habitat models and seasonal study site extents for the nesting life-stage

2. Regional boundary identification for sage-grouse habitat models and seasonal study site extents for the late brood-rearing (LBR)/summer life-stage ..............................

3. Regional boundary identification for sage-grouse habitat models and seasonal study site extents for the winter life-stage ..............................................................5

4. Diagram illustrating the modeled products for all life-stages, scales, and regions..........7

5. Seamless sage-grouse Boolean nesting habitat model showing the three separate regional models on one map..

6. Combined multi-scaled Boolean surfaces, which are stitched into statewide data

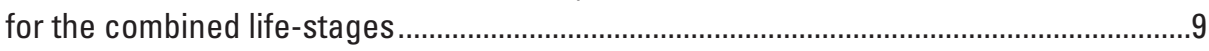

7. Graphical user interface of the Habitat Summary Tool ..................................................19 
8. Example of output graphs from the Habitat Summary Tool ............................................21

9. Graphical user interface and output from the Habitat Model Selection Tool ..................22

10. Required directory structure of downloaded data and software tools ...........................23

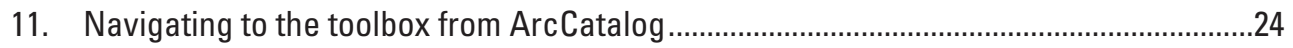

\section{Tables}

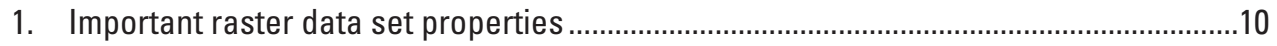

2. Classification scheme of Boolean and binned raster data sets ......................................10

3. Combined regional-multiscaled Boolean surfaces as statewide data for basic

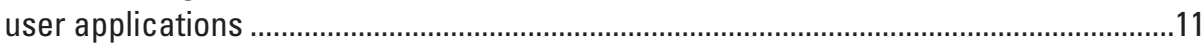

4. A matrix to select appropriate sage-grouse habitat models for advanced user

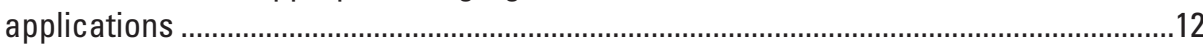

5. GIS data inputs for $A$, sage-grouse nesting, $B$, late brood-rearing summer, and

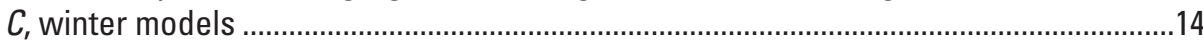

6. Description, data source, and spatial/temporal scales that apply to the GIS

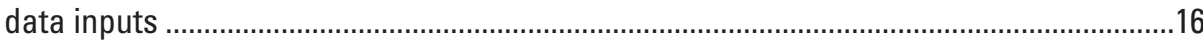

7. Descriptions of vegetation classes used for GIS data inputs ........................................17

8. Descriptions of hydrologic water body (areal features) classes used for GIS

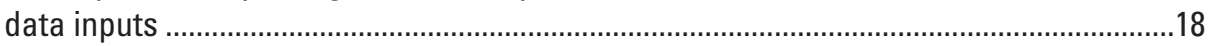

9. Descriptions of hydrologic water flow (linear features) classes used for GIS

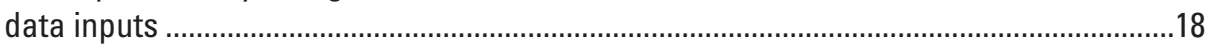

10. Descriptions of transportation classes used for GIS data inputs.....................................19

\section{Conversion Factors}

Inch/Pound to SI

\begin{tabular}{|c|c|c|}
\hline Multiply & By & \begin{tabular}{|l|} 
To obtain \\
\end{tabular} \\
\hline \multicolumn{3}{|c|}{ Length } \\
\hline foot $(\mathrm{ft})$ & 0.3048 & meter (m) \\
\hline mile (mi) & 1.609 & kilometer $(\mathrm{km})$ \\
\hline \multicolumn{3}{|c|}{ Area } \\
\hline acre & $\begin{array}{r}4,047 \\
2.590\end{array}$ & $\begin{array}{l}\text { square meter }\left(\mathrm{m}^{2}\right) \\
\text { square kilometer }\left(\mathrm{km}^{2}\right)\end{array}$ \\
\hline
\end{tabular}

Horizontal coordinate information is referenced to the World Geographic System of 1984 (WGS 84). 


\title{
Wyoming Greater Sage-grouse Habitat Prioritization: A Collection of Multi-scale Seasonal Models and Geographic Information System Land Management Tools
}

\author{
By Michael S. O'Donnell ${ }^{1}$, Cameron L. Aldridge ${ }^{2}$, Kevin E. Doherty ${ }^{3}$, and Bradley C. Fedy ${ }^{4}$
}

\section{Abstract}

With rapidly changing landscape conditions within Wyoming and the potential effects of landscape changes on sage-grouse habitat, land managers and conservation planners, among others, need procedures to assess the location and juxtaposition of important habitats, land-cover, and land-use patterns to balance wildlife requirements with multiple human land uses. Biologists frequently develop habitat-selection studies to identify prioritization efforts for species of conservation concern to increase understanding and help guide habitat-conservation efforts. Recently, the authors undertook a large-scale collaborative effort that developed habitat-selection models for Greater Sage-grouse (Centrocercus urophasianus) across large landscapes in Wyoming, USA and for multiple life-stages (nesting, late brood-rearing, and winter). We developed these habitat models using resource selection functions, based upon sage-grouse telemetry data collected for localized studies and within each life-stage. The models allowed us to characterize and spatially predict seasonal sage-grouse habitat use in Wyoming. Due to the quantity of models, the diversity of model predictors (in the form of geographic information system data) produced by analyses, and the variety of potential applications for these data, we present here a resource that complements our published modeling effort, which will further support land managers.

We deliver all products described herein as online geographic information system data for visualization and downloading. We outline the data properties for each model and their data inputs, describe the process of selecting appropriate data products for multifarious applications, describe all data products and software, provide newly derived model

${ }^{1}$ U.S. Geological Survey.

${ }^{2}$ Department of Ecosystem Science and Sustainability and Natural Resource Ecology Laboratory, Colorado State University, in cooperation with U.S. Geological Survey.

${ }^{3}$ U.S. Fish and Wildlife Service.

${ }^{4}$ Natural Resource Ecology Laboratory, Colorado State University and Environment and Resource Studies, University of Waterloo in cooperation with U.S. Geological Survey. composites, and discuss how land managers may use the models to inform future sage-grouse studies and potentially refine conservation efforts. The models, software tools, and associated opportunities for novel applications of these products should provide a suite of additional, but not exclusive, tools for assessing Wyoming Greater Sage-grouse habitats, which land managers, conservationists, and scientists can apply to myriad applications.

\section{Sage-grouse Habitat}

\section{Background}

Greater Sage-grouse (Centrocercus urophasianus; hereafter sage-grouse) habitat is limited to western semi-arid landscapes in North America, and because of documented range-wide population declines (Connelly and Braun, 1997; Christiansen, 2000; Garton, 2011), the species is currently listed as "warranted but precluded" under the U.S. Endangered Species Act (U.S. Fish and Wildlife Service 2010). With increased needs for land managers to identify sage-grouse habitat, Fedy and others (2014) developed sage-grouse seasonal habitat models for the nesting (March 1-June 15), late brood-rearing/summer (June 15-August 31), and winter (November 1-February 31) life-stages. The spatially explicit Wyoming habitat models presented in this report are the modeled results produced by Fedy and others (2014). This report additionally provides: a mosaic of the regional models represented for each life-stage as a statewide spatial data set (hereafter, seamless regional models), life-stage composites (combined nesting, late brood-rearing, and winter habitats), Geographic Information System (GIS) software, and explanation of data applications. These additional products and explanations are designed to better support land managers with their decision-making processes, while Fedy and others (2014) provide the more complex descriptions, modeling procedures, model accuracies, and other relevant information. Our objective is to provide the data products and tools to supplement the primary scientific publication (Fedy and others, 2014), as a way to increase the interpretation and usability 
of the model products in sagebrush-habitat management and sage-grouse conservation planning. We highly recommend that all data users also review the scientific publication (Fedy and others, 2014) where the authors thoroughly describe the modeling and evaluation efforts.

The habitat models focus on three life-stages (nesting, late brood-rearing/summer, and winter), which are important for understanding sage-grouse habitat associations and for management applications. Leks are communal breeding grounds where sage-grouse gather during the spring to perform ritualistic courtship displays and mate (Jiguet and others, 2000). These are generally open areas with minimal vegetation such as bare soil, open grass cover, or windswept ridges (Connelly and others, 2004). Lek sites are also juxtaposed to dense shrub-steppe for concealment from predators, as well as for thermal regulation and feeding cover (U.S. Fish and Wildlife Service, 2010). Within southwest Wyoming, 64 percent of lek locations are within 3-5 kilometers $(\mathrm{km})$ of nesting locations (Holloran and Anderson, 2005), but these distances vary with respect to varying habitat conditions occurring in different locations (Connelly and others, 2011; U.S. Fish and Wildlife Service, 2010). Nesting habitat occurs near sagebrush canopy cover with an understory of herbaceous plants and grasses (Shepherd and others, 2011). The sagebrush provides cover while hens incubate eggs, and the understory herbaceous plants provide habitat in which the sage-grouse can prey on insects and forage. Early brood-rearing occurs near nesting sites, but sage-grouse require less densely covered sagebrush and more abundant herbaceous cover for foraging (Connelly and others, 2011).

Hens and broods later seek moist landscapes (mesic) for nutritional components, such as the availability of herbaceous plants, insects, (Stiver and others, 2006; Stiver and others, 2010) and succulent vegetation during late brood-rearing as sagebrush habitat begins to dry out. Sage-grouse move from upland sagebrush areas to mesic areas during late broodrearing due to the desiccation of herbaceous plants (Connelly and others, 2000). During the winter, sage-grouse forage on sagebrush leaves and buds, and they rely on sagebrush for protection (Connelly and others, 2000); consequently, during the winter seasons, sagebrush must adequately protrude above snow cover. This means, sage-grouse often rely on windswept ridges where the sagebrush is typically not obstructed by deposited snow due to the topography and wind effects (Stiver and others, 2010). For additional information, Fedy and others (2012) explore Wyoming sage-grouse movements between seasons.

This basic synopsis of sage-grouse ecology is not intended to be a comprehensive description of the species' biology; rather, it is offered as a basic reference to help users contextualize the connection between sage-grouse habitat use and the provided spatial data sets. Such relationships are increasingly important to understand since sage-grouse habitat is changing rapidly with increased multi-use conditions in sagebrush communities. These life-stage habitat requirements are discussed further in Fedy and others (2014), and the compiled information provided captures current habitat conditions within Wyoming, and in this report, we provide a set of tools with guidance to enable land managers to begin exploring and applying these models for conservation practices.

\section{Models}

Habitat suitability models, and specifically Resource Selection Function (RSF) models, capture the relationships between landscape pattern(s) and a species' selection of a particular location and environmental conditions. These models quantitatively describe a relative probability of the species using a certain area (that is, a raster pixel) on the landscape, given the resource conditions associated within and around that location. With RSF models, landscape conditions at occupied resource units (telemetry locations) are compared to a sample of available resources. This allows the development of models that predict the relative probability that any given pixel on the landscape might be selected for use by the species (Manly and others, 2002). Fedy and others (2014) compiled sagegrouse location data from multiple unique radio-telemetry studies in Wyoming (contributions are described in the "Acknowledgements" section) to represent the three life-stages (nesting, late brood-rearing/summer, and winter) and habitat conditions for these locations, from high-quality, biologically relevant spatial information.

The GIS data layers represent available resources, thereby defining areas surrounding and encompassing each study site. Representative areas were confined to seasonal movement distances derived using the telemetry data (see Fedy and others, 2012; Fedy and others, 2014). To develop models that distinguish landscape conditions within the study sites from the surrounding available resources, these surrounding areas were contrasted with the landscape conditions used at each sage-grouse telemetry location. Fedy and others (2014) describe the details for developing these models as well as the results (for example, coefficients and standard errors) and model evaluations.

Because sage-grouse habitat selection in Wyoming varies spatially across regions and temporally among seasons, we independently modeled each life-stage statewide and for each region (southwest, central, and northeast; fig. 1) by using the respective subsets of the telemetry data during the modeling process. We developed the sub-regions using the National Hydrologic Database Unit Codes (HUC-2) polygonal data and the two sage-grouse management zone boundaries. Connelly and others (2004) provided the background on the different management zones. Stiver and others (2006) developed the management boundaries via the Western Association of Fish and Wildlife Agencies, and the Remote Sensing and GIS (RS/GIS) Laboratory at Utah State University digitized the figures within Stiver and others (2006). We refined the regional boundaries based on study site boundaries and expert knowledge. Because some telemetry locations fall in adjoining regions, we assigned the study site boundaries, and associated telemetry data, to a single region during modeling procedures. The Southwest region includes these study sites (also referred to as Study Area Extents): Jackson, Kemmerer, Pinedale, Farson, Hiawatha, 


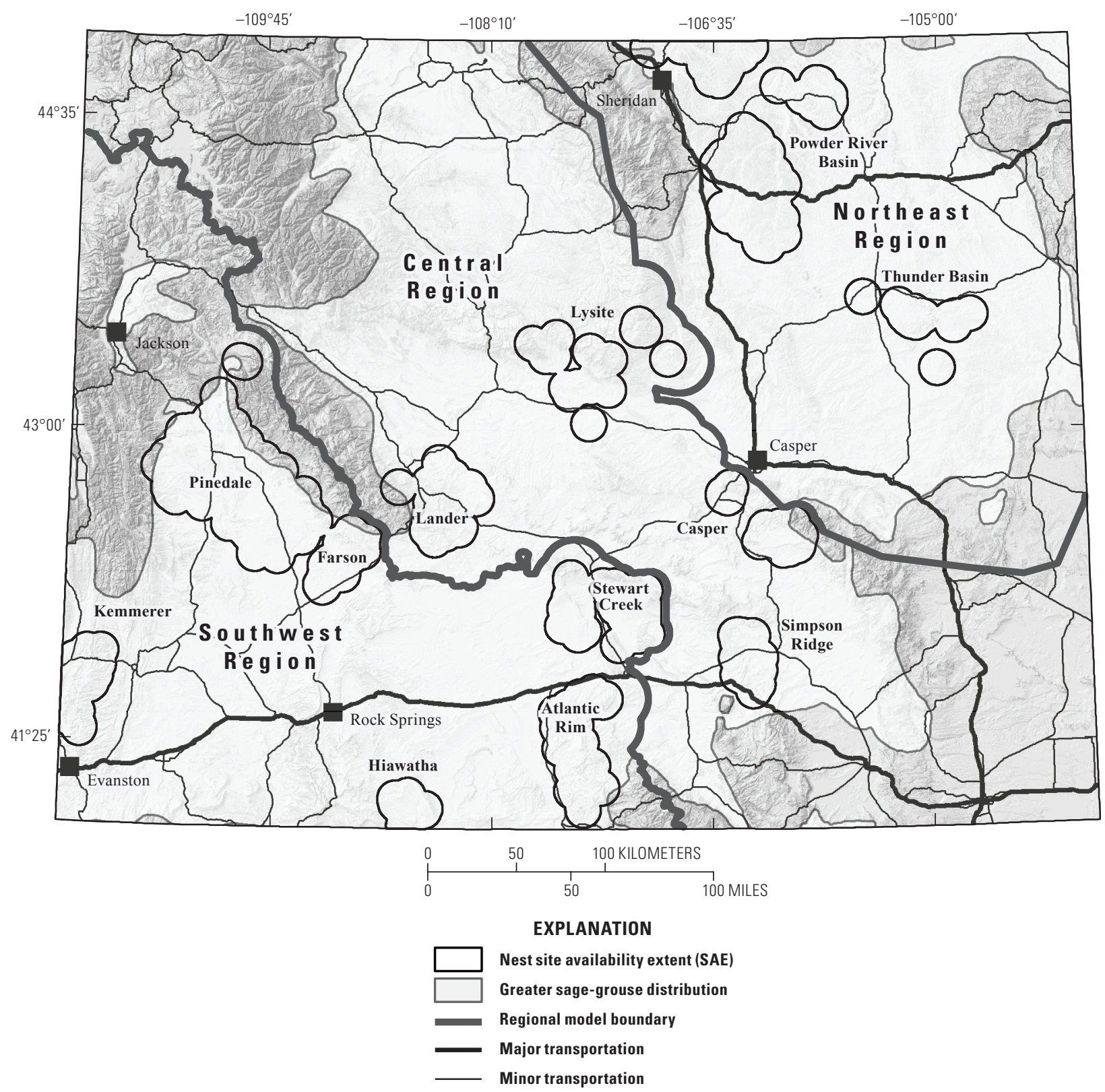

Figure 1. Regional boundary identification for sage-grouse habitat models and seasonal study site extents for the nesting life-stage.

Atlantic Rim, and Steward Creek. The Central region includes these study sites: Simpson Ridge, Lander, Lysite (Moneta), and Casper. The Northeast region includes these study sites: Powder River Basin, Thunder Basin, and Hulett. Not all study sites were used in all three life-stage habitat predictions. The following figures illustrate the study sites used for the nesting (fig. 1), late brood-rearing (LBR)/summer (fig. 2), and winter (fig. 3) lifestage habitat predictions.

Since sage-grouse select biologically relevant landscape characteristics across multiple spatial scales, Fedy and others (2014) included data types such as vegetation, topographic, anthropogenic, and hydrological spatial data at five different spatial extents. We categorized these five spatial extents into three different representative scales (patch, landscape, and combined [landscape-patch]). The patch scale model incorporates information influential to sage-grouse habitat selection via small distances surrounding the individual locations (radii of $0.045 \mathrm{~km}$ [0.006 square kilometers $\left.\left(\mathrm{km}^{2}\right)\right]$ and $0.564 \mathrm{~km}$ $\left.\left[1 \mathrm{~km}^{2}\right]\right)$. The landscape scale model incorporates information influential to sage-grouse habitat selection via large distances from locations $\left(1.5 \mathrm{~km}\left[7.07 \mathrm{~km}^{2}\right], 3.2 \mathrm{~km}\left[32.17 \mathrm{~km}^{2}\right]\right.$, and $6.44 \mathrm{~km}$ [that is, 4 square miles, $\left.138.67 \mathrm{~km}^{2}\right]$ ). The multiplicative, combined landscape and patch scale model (hereafter, landscape-patch) weights the influence of the two selection processes to create the third model structure.

Testing and comparing the different scales provides a means to highlight the different selection mechanisms exhibited by sage-grouse. To create these different scale effects, Fedy and 


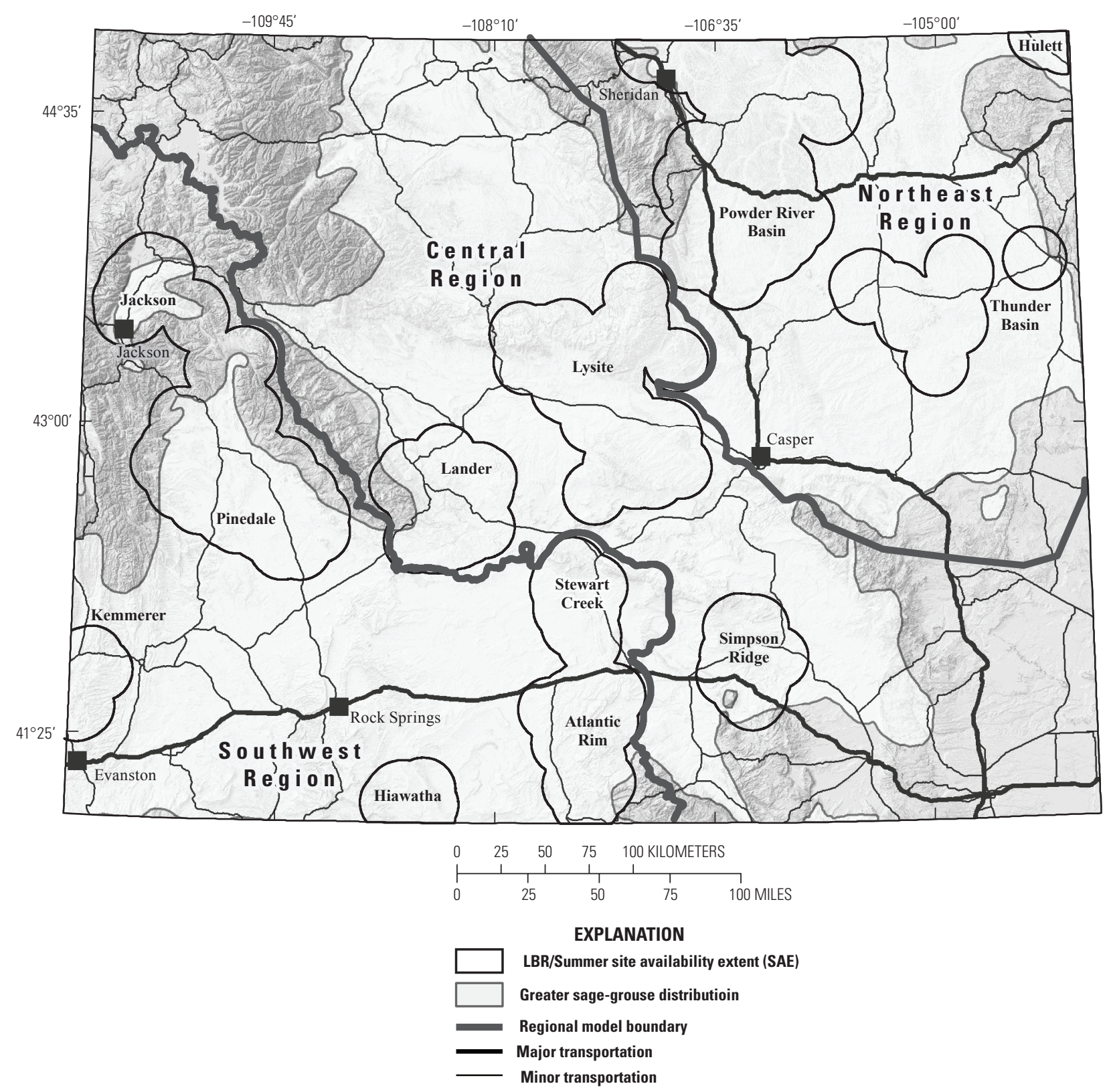

Figure 2. Regional boundary identification for sage-grouse habitat models and seasonal study site extents for the late brood-rearing (LBR)/summer life-stage.

others (2014) used neighborhood statistics (that is, moving window or kernel) on the input spatial data sets (raster file format). A kernel is a matrix or subset of the raster surface, for example, 3 rows and 3 columns of pixels. In a kernel-based analysis, the GIS software traverses the input raster data set and summarizes the pixels within the kernel while assigning a summary statistic (for example, mean and standard deviation) to the target cell (center cell of kernel) of the output data set. Different window sizes (that is, varying sized kernels) capture and differentiate the effects of biotic, abiotic, and anthropogenic conditions that may influence the processes of sage-grouse habitat selection at a given area (that is, scale). Relevant questions for conservation and management decisions may include: how do sage-grouse select an area during nesting because of the available resources in their immediate environment, and do they require similar or different resources within a larger landscape-scale area (for example, $16 \mathrm{~km}^{2}$ )? Considering these different scales allows the model users to estimate how neighboring conditions affect habitat suitability, which provides information that is difficult to assess directly with field observations.

After we developed the RSF models within a statistics software package, we applied the statistical relationships to the relevant spatial data, which resulted in RSF continuous raster surfaces (pixel values range between 0.0 and 1.0). Because the RSF pixel values are not directly comparable between regions or life-stages (that is, a value of 0.5 is not necessarily equivalent or directly comparable across different models), we classified the pixel values into bins of habitat importance using 


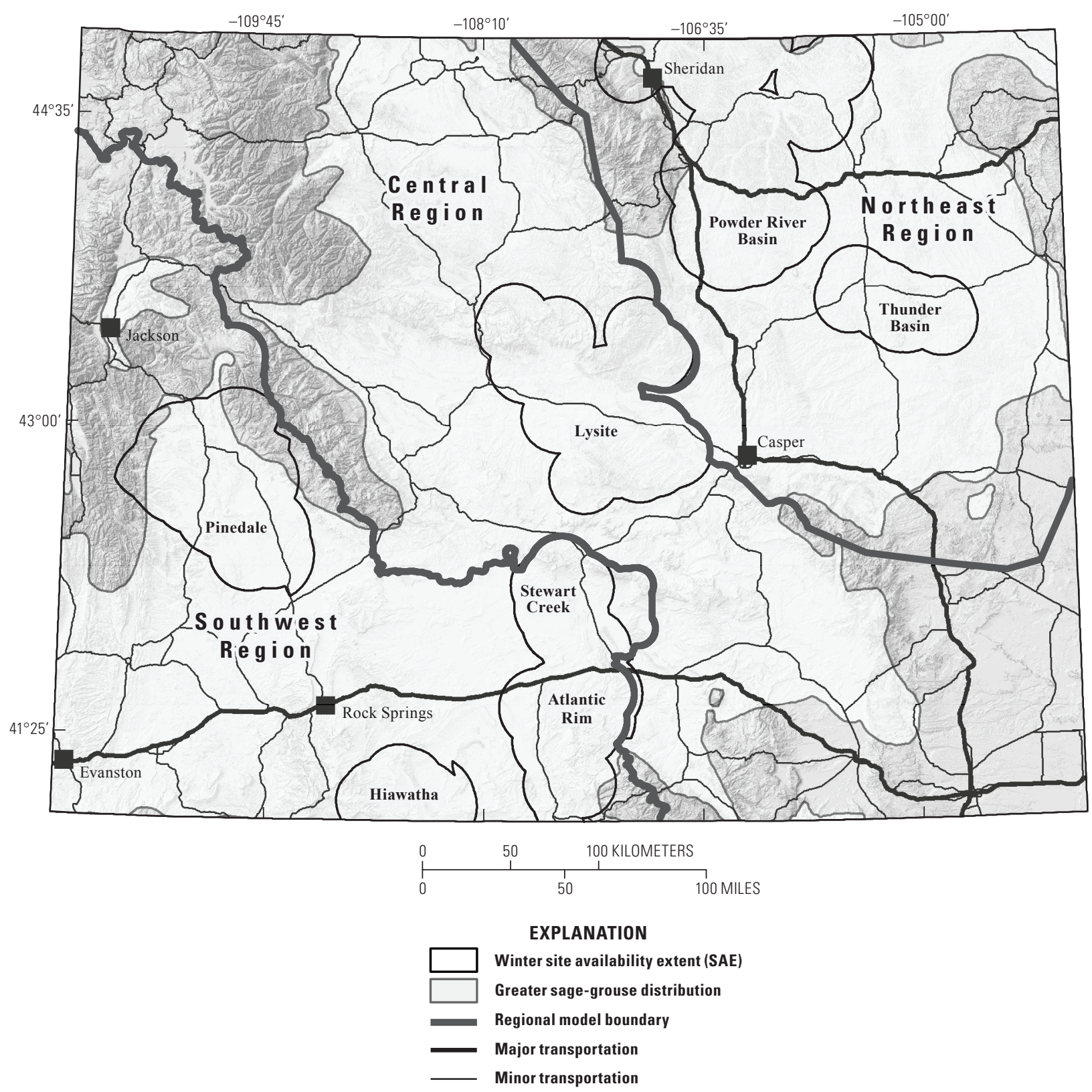

Figure 3. Regional boundary identification for sage-grouse habitat models and seasonal study site extents for the winter life-stage.

a statistically driven thresholding approach. This approach was determined for each specific model based on the telemetry data used during model development (Fedy and others, 2014). The approach, developed by David L. Gummer and Cameron L. Aldridge (see the "Acknowledgements" section and the summary in Fedy and others, 2014), is a modification of methods first introduced by Hirzel and Arlettaz (2003) and Hirzel and others (2006). The thresholding process compares the proportion of locations occurring within the predicted habitat for a given threshold with the proportion of locations occurring within the predicted habitat by chance across a range of potential threshold values. Using this method, Fedy and others (2014) developed an optimized binary response raster surface (habitat versus non-habitat) via a single RSF threshold for each model. They also used the selected RSF threshold and its confidence intervals to create a binned response surface to classify habitat further into three classes (less, more, and most habitat potential) surrounding the identified threshold (see Fedy and others, 2014).

Fedy and others (2014) evaluated model performance using sage-grouse telemetry data withheld from model development of each season, lek data for nesting models, and data from a new nesting study located in Worland Basin (north central Wyoming). The withheld data evaluations occurred within study sites; therefore, they did not evaluate model performance as extensively for regions falling outside of the study sites. However, they evaluated regional nesting models outside of study sites using lek data distributed across the state as a proxy for nesting use. Fedy and others (2014) provide discussion on the RSF model performance in detail. 


\section{GIS Data Sets}

\section{Background}

There are three main types of raster GIS data sets accompanying this report: RSF continuous predictions (values between 0.0 and 1.0), Boolean classification of each RSF model (habitat versus non-habitat), and a binned classification of each RSF model (less, more, and most habitat potential based on thresholding and confidence intervals). The RSF models represent the relative importance of habitat selection for any given life-stage and region. Although each statistical model was developed for a specific region (state, southwest, central, northeast), we created statewide raster data sets by applying the RSF statistical model to a statewide spatial extent. The RSF model uses logistic regression (equation 1) to model the importance of each predictor (for example, sagebrush cover or distance to road), predicting the relative probability of habitat selection $p(x)$, in this case,

$$
p(x)=\frac{e^{\left(\beta_{0}+\beta_{1} x+\beta_{2} x+\ldots+\beta_{n} x\right)}}{e^{\left(\beta_{0}+\beta_{1} x+\beta_{2} x+\ldots+\beta_{n} x\right)}+1},
$$

where
$e \quad$ is the exponent of the quantity,
$\beta_{o} \quad$ is the intercept estimate, and
$\beta_{1-n}$ are coefficient estimates for the 1-to- $n$ predictors.

The equation was then used in GIS to produce a single continuous raster surface representing the relative probability of selection (RSF raster surfaces). These equations are provided in each GIS metadata product, which will allow advanced users to evaluate the habitat-selection processes.

To simplify the use of the models presented in this report, we developed three statewide models, one for each life-stage, by merging the three different regional RSF models (Binned and Boolean) within each season into a single data set. Because the RSF surfaces are not directly comparable between regions, we did not create a mosaic of the regional RSF continuous surface models into a statewide spatial extent. For each life-stage, we clipped the regional model for the Boolean (that is, presence/absence; habitat/non-habitat) raster surface to its respective region and then merged the three regions into a single data set. We then repeated these processes for the regional binned models. A summary of the different models as well as their appropriate use is outlined below.

1. Fedy and others (2014) developed all statistical model combinations (fig. 4) using sage-grouse telemetry data from local sage-grouse studies occurring across the state and collected between 1994 and 2010. The study area extents were defined using data gleaned from movement distances between life-stages (Fedy and others, 2012).

- The model accuracies are well known within study sites and less understood in novel areas (see Fedy and others, 2014).
- Using these habitat models in novel areas (that is, locations falling outside of the seasonal study site extents) requires careful scrutiny and knowledge of sage-grouse habitat. Since there were limited data to evaluate nesting, late brood-rearing, and winter models in novel areas, potential users can assess these models using newly collected sage-grouse telemetry data before making decisions about their use for informing management decisions.

- If newly collected data do not exist for novel areas, we suggest using the combined landscape-patch regional models or the statewide landscape-patch models for habitat assessments because these models capture the best biologically relevant information and at the scales relevant to sage-grouse habitat selection.

- The regional models (southwest, central, northeast) use telemetry data located from their respective region. However, we applied each regional statistical model to the statewide extent, which results in an RSF surface predicted to the entire state of Wyoming.

- Evaluating one regional model in a different region (for example, southwest model applied to the central and northeast region) may provide insight into how to improve the regional boundaries by identifying similarities/dissimilarities. These regional comparisons may also be useful for examining where researchers might initiate new sage-grouse studies to improve future-modeling efforts. For example, if an area within the southwest model performed better while using the central model, then this could signify landscape similarities in the southwest relative to studies used in the central model.

- Assessing habitat importance using a regional model that was designed for a different region is a method for aiding with future model improvements and not a tool for identifying habitat. Based on model evaluations and statistical approaches, the model that Fedy and others (2014) developed for a specific region is considered the best model available with respect to capturing the majority of use and evaluation locations. Data users should refer to Fedy and others (2014) for specific details on the evaluation differences of the regional and statewide models. However, if a portion of a modeled region performs better while using a different regional model, then managers and researchers may develop new studies within the region to improve future modeling efforts.

2. The statewide models use all available telemetry data across the state of Wyoming for each season.

- These models perform similarly to the regional models, and we include them because they provide a means for evaluating strengths and weaknesses between statewide and regional modeling approaches. They can 


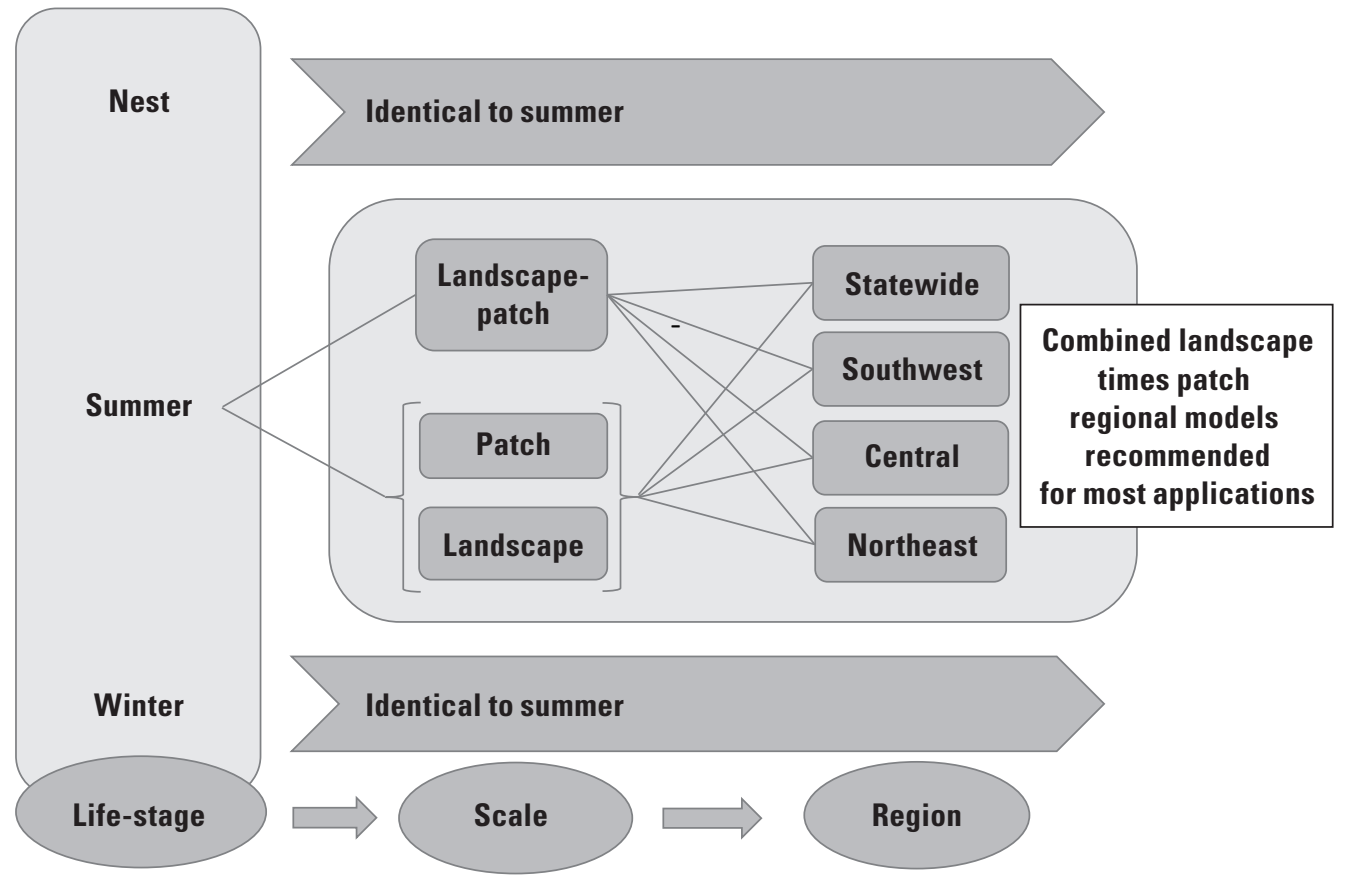

Figure 4. Diagram illustrating the modeled products for all life-stages, scales, and regions.

also be useful for considering potential segregation of the management regions. The regional models capture more use and evaluation locations, but at the cost of implicating a slightly larger portion of the landscape (that is, there is less discriminatory power; Fedy and others, 2014)

3. RSF relative probability surfaces versus Boolean and binned surfaces.

- The RSF continuous surfaces are provided if users want to explore or alter the thresholding, which may be desired for novel assessments. Thresholding does not change the statistical relationships with individual covariates that are inherent in the RSF relative probability surfaces. However, this process does change the classification of the modeled surfaces (for example, multiple bins of varying habitat importance).

- While there are multiple different options to identify the specific threshold choice, the approaches we used are statistically defensible and repeatable across models and areas. Such alternative methods range from quasi-continuous bins of different percentages of the data to looking for natural breaks in data values (Boyce and Waller, 2000). To understand the range of variability in the data, managers may evaluate the continuous RSF raster surfaces by selecting a large number of bins (for example, 20) and then decrease the number of bins to refine the thresholds based on the user's needs. A larger number of bins allows greater amounts of variability to be illustrated. Users can first apply the Boolean and binned habitat surfaces with their region of interest first, and then possibly explore the continuous RSF surface to gain further insights into habitat quality within or surrounding the areas of interest.

- If new telemetry data becomes available for novel areas, these spatial data can be used to threshold the existing RSF surfaces for the local area. The thresholding process we used for this report is complex and computationally intensive; thus, we developed a GIS tool for automating and standardizing the process. However, due to its complexity, we are not distributing the thresholding software with this report.

- Data users can refer to the Federal Geographic Data Committee (FGDC) compliant metadata developed for each data product, Fedy and others (2014), and tables $5 A-5 C$ for details on regression coefficients applied to each model. The coefficients provide the relationships (magnitude and direction) of habitatselection processes, and they are very important for understanding the biological relationships between sage-grouse and the individual predictors.

4. Scales for, and selection of, habitat suitability.

- In most cases, the combined landscape-patch scale models are the best habitat predictions, because sagegrouse select habitat using information represented at different spatial scales (Fedy and others, 2014). For this reason, we provide seamlessly stitched (mosaic of the regional Boolean and binned models into a statewide spatial extent) statewide regional landscape-patch models for each life stage so the data are easier to work with (fig. 5). 


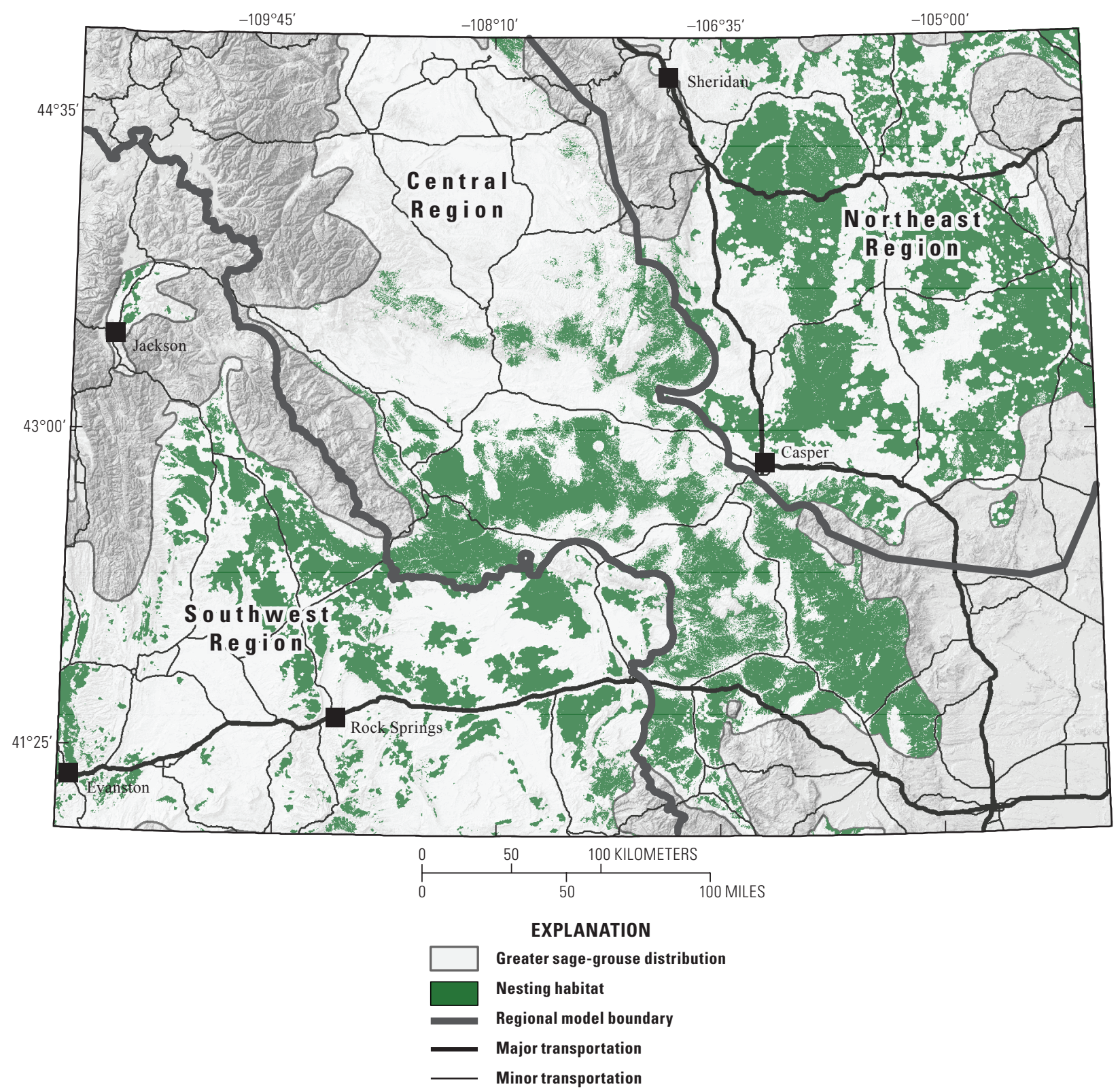

Figure 5. Seamless sage-grouse Boolean nesting habitat model showing the three separate regional models on one map. Late brood-rearing and winter models are not shown and binned seamless regional models are also not shown.

- We provide the individual landscape and patch models so users can thoroughly explore habitat selection for different processes. For example, with newly collected local sage-grouse telemetry data, users can evaluate the habitat-selection processes occurring at the different scales (landscape and patch). A user may also use these individually scaled products to explore different scenarios of scale dependence, such as those methods outlined in DeCesare and others (2012) and Aldridge and others (2012). With the use of telemetry data and thresholding approaches, the spatial agreement of habitat versus nonhabitat between the two scales can indicate differences in selection processes for different areas.
- We combined all seasons and regions to create a statewide seamless data set; this will allow for assessments of sage-grouse habitat based on the combined life-stages (fig. 6).

The data accompanying this report (GIS Data Download) are mostly raster data sets, and users can explore all products within most GIS (open source and proprietary) software. Descriptive properties of the raster data sets, file naming convention, and coordinate system that are important for consideration by users have been summarized (table 1). We describe the classification scheme used for the Boolean and discrete habitat models to facilitate understanding and proper 


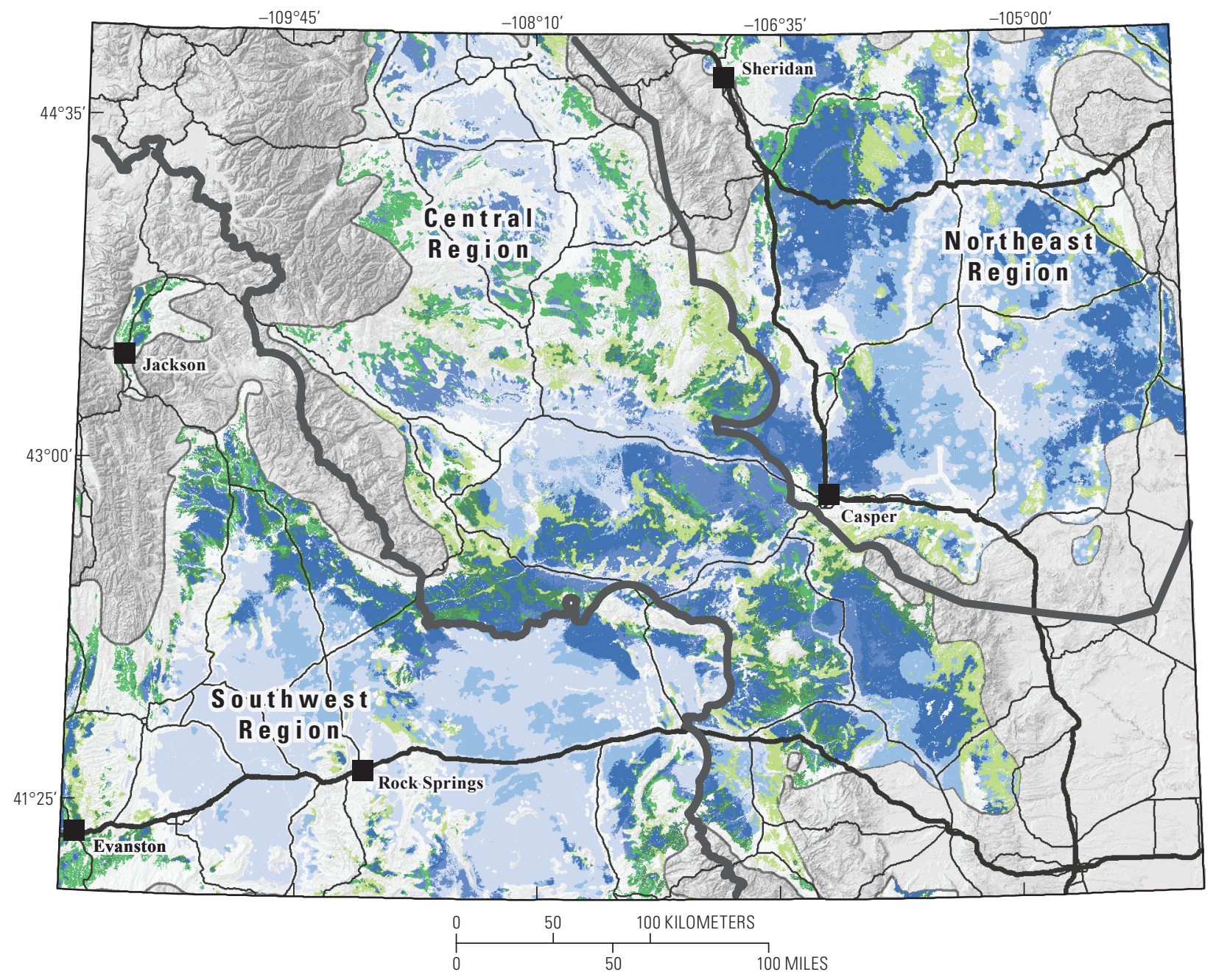

EXPLANATION
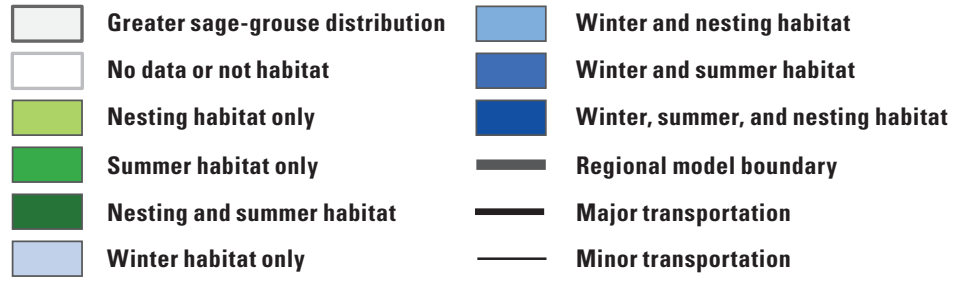

Figure 6. Combined multi-scaled Boolean surfaces, which are stitched into statewide data for the combined life-stages.

application (table 2). Each data set includes a FGDC metadata file that describes in detail the data inputs and processes used to develop the specific model. Fedy and others (2014) report the details of the methods used for model development.

\section{Basic Spatial Applications}

For most applications that require spatial information of sage-grouse habitat models, the Boolean (habitat versus nonhabitat) and binned data products are recommended, unless new data is available to help inform an appropriate model selection. There are six seasonal data products (3 Boolean and 3 binned) that represent a mosaic of the regional models to create a statewide spatial extent (not to be confused with the statewide model; table 3 ). These results provide the products that will meet most land managers' needs (for example, mosaics of regional Boolean and binned habitat models and seasonal composites; table 3). To help guide suitable land management applications, we developed examples for these products.

1. Quantify the amount of habitat within land-management units, ecoregions, environmental assessment boundaries, watersheds, or similar management parcels.

2. Examine the area (patch size) and connectivity of habitats. Highlight conservation needs by evaluating area and habitat connectivity to identify regions of intactness. 
Table 1. Important raster data set properties.

$[\mathrm{m}$, meters]

\begin{tabular}{|c|c|c|c|}
\hline Dataset Property & Boolean & Binned & Continuous \\
\hline Bit Type & 8 Bit UN & IGNED & 32-bit floating \\
\hline Map Projection & \multicolumn{3}{|c|}{ U.S. Albers Conic Equal Area with datum WGS84 } \\
\hline
\end{tabular}

wysg: Wyoming Sage-grouse

[scale]: this is replaced with 'l' (landscape), 'p' (patch), or 'lp' (landscape-patch). These represent the scale of the data used for deriving the model.

[region]: this is replaced with 'sw' (southwestern region of Wyoming), 'central' (central region), or 'ne' (northeastern region).

[season]: this is replaced with 'nest' (nesting habitat), 'summer' (late brood-rearing habitat), or 'winter' (winter habitat).

Table 2. Classification scheme of Boolean and binned raster data sets.

[RSF, Resource Selection Function]

\begin{tabular}{|c|c|}
\hline Class & Description \\
\hline 1 & Potential habitat \\
\hline 0 & Represents no data values occurring within the Western U.S. Sage-grouse distribution and current model, which we did not predict to. \\
\hline 1 & Non-potential habitat (all RSF values falling below the lower confidence interval) \\
\hline 2 & Potential habitat least probable (lower confidence interval to selected threshold) \\
\hline \multicolumn{2}{|r|}{ Combined Seasonal Boolean } \\
\hline 0 & No data or no habitat \\
\hline 1 & Nesting habitat only \\
\hline 10 & Summer habitat only \\
\hline 11 & Nesting and summer habitat congruence \\
\hline 100 & Winter habitat only \\
\hline
\end{tabular}

The seasonal data products can also be used to compare sage-grouse habitat connectivity under potential land-use scenarios to prioritize conservation needs and options.

3. Compare seasonal habitat models with management zones with assigned specific sage-grouse habitat regulations (for example, core areas and priority habitats). Evaluate congruence between the habitat models and existing protections and identify gaps in both core area and (or) the habitat models when expert opinion and (or) field assessments are interjected. The core area management zones are based on lek sites, sage-grouse movement distances to nest sites, male attendance at leks, expert knowledge, and management needs, whereas the sage-grouse habitat models reflect statistical models of sage-grouse habitat for nesting as well as two additional life-stages. The combination of resources can help land managers make informed decisions of sage-grouse habitat and conservation efforts.
4. Examine sage-grouse habitat congruence with land health standards (range management/conditions) and prioritize conservation needs.

5. Monitor land-use or land-condition changes with respect to sage-grouse habitat at a regional scale (refer to the "Frequently Asked Questions" section).

6. Examine potential development scenarios (for example, potential location of renewable energy facilities) and sage-grouse habitat model projections to prioritize conservation by avoiding and mitigating conflict and impacts.

\section{Advanced Spatial Applications}

In some cases, managers and researchers may want to ask more complex questions with these products. We developed a matrix of data products for the regional models of each life-stage to help categorize the data and allow users to 
Table 3. Combined regional-multiscaled Boolean surfaces as statewide data for basic user applications.

\begin{tabular}{lc}
\hline & Nest \\
\hline $\begin{array}{l}\text { Boolean } \\
\text { Binned }\end{array}$ & wysg_lp_regional_nest_bool.tif \\
\hline & wysg_lp_regional_nest_bin.tif \\
\hline $\begin{array}{l}\text { Boolean } \\
\text { Binned }\end{array}$ & Summer \\
\hline \multicolumn{2}{c}{ wysg_lp_regional_summer_bool.tif } \\
Boolean & wysg_lp_regional_summer_bin.tif \\
Binned & Winter \\
\hline & wysg_lp_regional_winter_bool.tif \\
\hline Boolean & Nest + Summer + Winter \\
\hline
\end{tabular}

identify the data product they would like to use (table 4). The "Background" section within "GIS Data Sets" outlines the differences between these products. We provide suggestions of examples and questions that land managers may investigate for advanced applications here.

1. Evaluate specific areas to identify those areas that do not appear to capture habitat well.

- Can we better capture habitat within these areas if the RSF model is thresholded differently? Data users can explore the use of a high number of bins and a quantile binning approach (refer to ESRI documentation) in GIS to visually assess models when comparing to independent data (see specifics below).

- Do any of the model predictors appear misrepresentative for the areas performing poorly? We do not provide model inputs with this product, but these data are all available online. U.S. Geological Survey Fort Collins Science Center has published the Wyoming transportation (circa 2009) data series (O'Donnell and others, 2014), which is an updated version of the transportation data used for developing the products within this report.

2. Are any models designed for one region performing better in a different region?

- Can the state be divided into better representative regions, which can be used in the development of future models? Changing the regional boundaries also requires having sage-grouse telemetry data that is well distributed within those regions.

- What areas do not appear to capture habitat well and how might the model be improved with new data inputs or re-shaping of regional boundaries?

3. Where are new sage-grouse study sites necessary to provide better spatial representation within each region?

4. Which models require improvement, and is this need a result of poor spatial distribution of existing sage-grouse studies or because of predictor data gaps? To resolve this question, refer to the models' logistic regression equations and predictors within the metadata to assess data gaps (consider quality, scale, omission [missing], and commission [data contains feature but feature does not exist on ground]).

5. Evaluate habitat model performance in novel areas (see the "Habitat Model Selection Tool" section).

6. Will including lower confidence intervals of the binned products improve the models for your area of interest? Are regions vastly different with respect to inclusion/exclusion of the lower confidence interval, and can this information be used to stratify locations for future studies?

7. A land manager may use the relations between sagegrouse habitat use and these predictors as an additional resource to inform land use regulations (for example, relative magnitude indicated by coefficients and direction [positive/negative association] indicating allurement or avoidance of specified conditions and anthropogenic land-use patterns). The relationships denoted within the RSF equations (logistic regression) can portray how sagegrouse react to different landscape characteristics, and this information can help inform land-use policies.

The thresholding approach used in Fedy and others (2014) is both CPU and memory intensive (up 170 hours of computing time), and providing this resource is beyond the scope of this project. However, one can manually threshold or bin the RSF surfaces, which will create a similar effect. We provide instructions on how one can examine the RSF models using visual cues.

1. For a new set of telemetry data in a novel area, extract pixel values at the point locations using the appropriate season and RSF regional model. If the telemetry data overlap two regions, select one of the two regional models or divide the telemetry data into two data sets and then follow the steps below. The easiest approach, and possibly the best approach to avoid using a small sample size, is to select the RSF model that contains the majority of the data. There is no recommended number of telemetry locations for this analysis, but users should consider the effects of temporal/spatial autocorrelation, a diverse and well-represented sample of habitat for the area of interest, and an appropriate sample size.

2. After the RSF pixel value is assigned to each point, sort the column with RSF pixel values in descending order. This column is located in the feature class (GIS vector data) table. Low RSF values indicate lesser habitatselection potential, and high RSF values indicate greater habitat-selection potential. Select the top 90 percent of the sorted telemetry locations (or a population threshold of interest: for example, 95 percent) and identify the smallest RSF value within this selection. 
Table 4. A matrix to select appropriate sage-grouse habitat models for advanced user applications.

[RSF, Resource Selection Function; L-p, denotes landscape-patch combined scales]

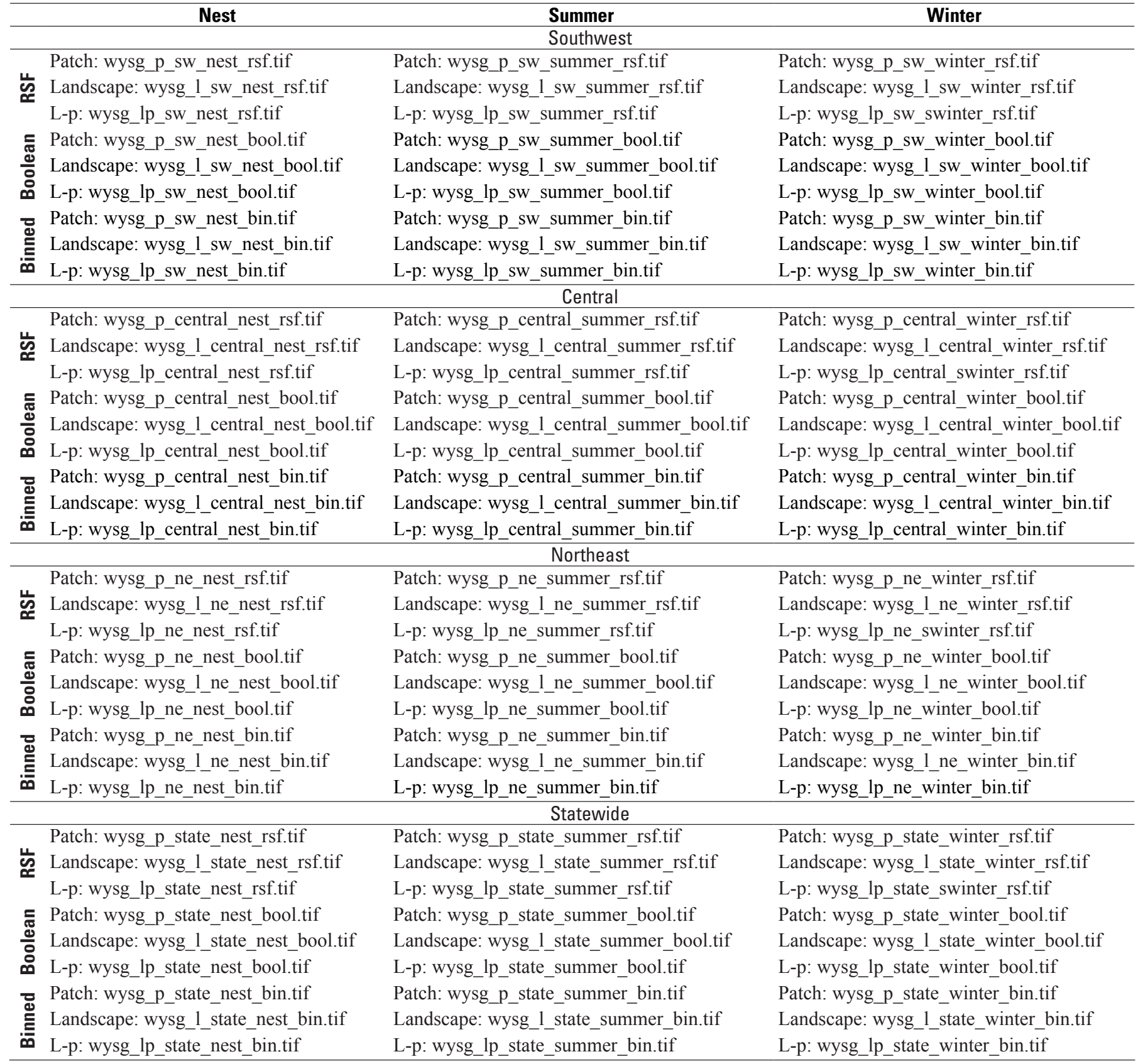

3. Using the selected RSF value, threshold the raster model, and produce a habitat/non-habitat data set. One can do this using a GIS conditional statement or reclassify GIS tool, but the easiest approach is to change the symbology. Changing the symbology does not require creating a new data set and therefore allows for quick exploration of different threshold values.

4. With RSF values assigned to the telemetry locations, one can select threshold values that result in a low to high habitat importance by selecting an RSF value associated with 0 percent -5 percent, 5 percent -10 percent, 10 percent -30 percent, 30 percent -50 percent, 50 percent -75 percent, and 75 percent -100 percent of the ascending, ranked RSF values assigned to the telemetry locations. Managers can customize these bins based on needs, and therefore, this is only an example. The larger the RSF value, the greater the probability sage-grouse will use the habitat. This approach bins the RSF values using the distribution of RSF values associated with the telemetry data. Alternatively, but in a less-informed 
fashion, the user can classify the RSF surface by binning the RSF values based on the distribution of the values across the data set. The latter approach is less informed by data because the telemetry data are not used to inform the binning process, but this is a common approach for interpreting RSF surfaces.

As demonstrated, a number of applications exist for evaluating sage-grouse habitat. With these potential permutations and questions, land managers can use these results to inform future studies and conservation efforts.

\section{Model Inputs}

Each model (life-stage, region, and scale) permutation will include different land cover/land use predictors. Table 5 describes model inputs, kernel radius, summary statistics, and model association (positive association for selecting habitat or negative association for avoidance). This information will allow users to assess the landscape characteristics that sagegrouse are selecting within a region, as well as across regions. The combined patch and landscape models are not listed in table 5 because they reflect the same results listed for the individual landscape and patch models.

We provide brief descriptions of the data sets used to create the individual predictors, which include data source, spatial scale/resolution, and time-stamp of source data. A user can therefore use table 6 to assess data-input information quality and the general quality of derived models. The scale and content of the source data are useful for understanding the propagation of errors introduced in the models. All data and models contain inaccuracies, and it is important for land managers to understand data-input limitations and to recognize ways to identify data needs for future model improvements. We also provide information describing how the source data inputs were re-classified to create the predictors for all vegetation classes (table 7). Details of the methods to reclassify hydrologic features used as predictors (table 8 and 9), and a list of the classes used to define the transportation data (table 10) outline how we altered data inputs of the models. Additional information about GIS data explored for model development of sage-grouse habitat was thoroughly described by Fedy and others (2014).

Some of the model inputs required calculations in GIS and therefore warrant some explanation in order for users to understand the implications of the information listed (table 1-5). The density of linear features defines the units of length per unit of area, while the density of point features is the density of points within a unit of area at each output raster cell. The decay function (equation 2), a method for evaluating the non-linear distance effects, produces a scale between 0.0 and 1.0 with high values representing close proximity to the feature. The coefficients associated with decays located in the metadata are interpreted opposite of coefficients associated with Euclidean distance. For example, a positive coefficient for Euclidean distance (as seen in the metadata $[+]$ ) indicates avoidance (as seen in table 5 [-]). A positive coefficient for decay distance indicates affinity for that land cover/land use because large decay distance values occur near features and decrease with increased distance from a feature.

$$
\operatorname{Exp}\left(\frac{\left(\begin{array}{c}
-1 * \text { Eucledian Distance between } \\
\text { target pixel and feature }
\end{array}\right)}{\text { Radius of Kernel }}\right)
$$

where

$\operatorname{Exp}() \quad$ is the exponent of the quantity.

\section{Data Set Quality Assurance}

The methods used for developing the sage-grouse models were peer-reviewed (Fedy and others, 2014). To further ensure data quality of the GIS data products, which we present with this report, we developed a Python ${ }^{\circledR}$ script that reports on dataset characteristics, including inconsistencies. The script first makes the following comparisons between raster data sets and flags any inconsistencies using the following criteria:

1. The number of rows and columns

2. Map projections

3. Bit type

4. RSF pixel values fall between 0.0 and 1.0

5. Boolean data sets are of integer type and fall within the set $\{0,1\}$

6. Binned data sets are of integer type and fall within the set $\{0,1,2,3,4\}$

7. Composite seasonal model data sets are of integer type and fall within the set $\{0,1,10,11,100,101,110,111\}$

The Python script is also used to automate the evaluation of FGDC metadata compliancy. All metadata were evaluated using the FGDC Metadata Parser software (MP, U.S. Geological Survey [USGS] http://www.fgdc.gov/metadata/ geospatial-metadata-tools) to ensure that no syntax errors exist within the metadata. These data and metadata have also undergone a peer-review process to ensure accurate reporting.

\section{Land Management Software Tools}

\section{Background}

In addition to this report and data products discussed in previous sections, we are also distributing an ESRI ArcToolBox ${ }^{\circledR}$ with two accompanying analytical tools to further aid land managers with using the presented sage-grouse models. These software tools require ESRI ArcGIS $₫$, and therefore, an ESRI Desktop ${ }^{\circledR}$ and Spatial Analyst ${ }^{\circledR}$ license. The first tool (Habitat Summary Tool) quantifies sage-grouse habitat areas for the multi-seasonal, multi-scaled (landscape, 
Table 5. GIS data inputs for $A$, sage-grouse nesting, $B$, late brood-rearing summer, and $C$, winter models.

[USGS, U.S. Geological Survey; SB, sagebrush; NA, not applicable; ppt, precipitation; MODIS NDVI, Moderate Resolution Imaging Spectroradiometer Normalized Difference Vegetation Index; ReGAP, Regional National Gap Analysis Program]

\begin{tabular}{|c|c|c|c|c|c|c|c|c|}
\hline Region & Landscape predictor & $\begin{array}{l}\text { Kernel } \\
\text { radius } \\
\text { (meters) }\end{array}$ & $\begin{array}{l}\text { Summary } \\
\text { statistic }\end{array}$ & Association & $\begin{array}{c}\text { Patch } \\
\text { predictor }\end{array}$ & $\begin{array}{l}\text { Kernel } \\
\text { radius } \\
\text { (meters) }\end{array}$ & $\begin{array}{l}\text { Summary } \\
\text { statistic }\end{array}$ & Association \\
\hline \multicolumn{9}{|c|}{$A$ Sage-grouse nesting } \\
\hline \multirow[t]{5}{*}{ State } & $\begin{array}{l}\text { All agriculture land } \\
\quad \text { (irrigated and non-irrigated) }\end{array}$ & 1,500 & mean & - & $\begin{array}{l}\text { All agriculture land } \\
\quad \text { (irrigated and non-irrigated) }\end{array}$ & 564 & decay & + \\
\hline & USGS all sagebrush & 1,500 & mean & + & USGS all sagebrush & 564 & mean & + \\
\hline & ReGAP forested land & 1,500 & decay & - & ReGAP forested land & 564 & decay & + \\
\hline & Transportation classes $1-2$ & 3,200 & density & - & Transportation classes $1-2$ & 564 & decay & + \\
\hline & & & & & USGS shrub height & 45 & mean & + \\
\hline \multirow[t]{3}{*}{ Northeast } & $\begin{array}{l}\text { All agriculture land } \\
\quad \text { (irrigated and non-irrigated) }\end{array}$ & 1,500 & decay & + & $\begin{array}{l}\text { All agriculture land } \\
\quad \text { (irrigated and non-irrigated) }\end{array}$ & 564 & decay & + \\
\hline & USGS all sagebrush & 6,400 & mean & + & USGS all sagebrush & 564 & mean & + \\
\hline & Transportation classes $1-2$ & 6,400 & density & - & Transportation classes $1-2$ & 564 & decay & + \\
\hline \multirow[t]{5}{*}{ Central } & Agriculture non-irrigated land & NA & $\begin{array}{c}\text { Euclidean } \\
\text { distance }\end{array}$ & - & USGS all sagebrush & 45 & mean & + \\
\hline & USGS all sagebrush & 3,200 & mean & + & & & & \\
\hline & ReGAP forested land & NA & $\begin{array}{c}\text { Euclidean } \\
\text { distance }\end{array}$ & - & & & & \\
\hline & Transportation classes $1-2$ & 6,400 & density & - & Transportation classes $1-2$ & 564 & decay & + \\
\hline & 2008 oil and gas well locations & 3,200 & density & - & & & & \\
\hline \multirow[t]{8}{*}{ Southwest } & Agriculture non-irrigated land & NA & $\begin{array}{c}\text { Euclidean } \\
\text { distance }\end{array}$ & + & & & & \\
\hline & USGS all sagebrush & 1,500 & mean & + & USGS all sagebrush & 564 & mean & + \\
\hline & ReGAP forested land & 1,500 & decay & + & ReGAP forested land & 564 & decay & + \\
\hline & Transportation classes $1-2$ & 3,200 & density & - & Transportation classes $1-2$ & 564 & decay & + \\
\hline & & & & & USGS herbaceous & 564 & mean & + \\
\hline & & & & & USGS herbaceous & 564 & $\begin{array}{l}\text { standard } \\
\text { deviation }\end{array}$ & - \\
\hline & & & & & Terrain ruggedness & 564 & NA & - \\
\hline & & & $B \quad \mathrm{La}$ & e brood-rearin & g summer & & & \\
\hline \multirow[t]{10}{*}{ State } & Agriculture non-irrigated land & 6,400 & mean & - & Agriculture non-irrigated land & 564 & decay & + \\
\hline & USGS all sagebrush & 3,200 & mean & + & USGS all sagebrush & 564 & mean & + \\
\hline & USGS all sagebrush & 3,200 & $\begin{array}{c}\text { standard } \\
\text { deviation }\end{array}$ & + & USGS all sagebrush & 564 & $\begin{array}{l}\text { standard } \\
\text { deviation }\end{array}$ & + \\
\hline & USGS herbaceous & 1,500 & mean & + & USGS herbaceous & 45 & mean & + \\
\hline & ReGAP forested land & 3,200 & mean & - & ReGAP forested land & 564 & decay & + \\
\hline & USGS shrub height & 6,400 & mean & + & & & & \\
\hline & $1971-2000$ normals ppt & 1,500 & mean & + & 1971-2000 normals ppt & NA & NA & + \\
\hline & $\begin{array}{l}\text { 1971-2000 normals ppt } \\
\quad \text { (quadratic) }\end{array}$ & 1,500 & mean & - & $\begin{array}{l}\text { 1971-2000 normals ppt } \\
\text { (quadratic) }\end{array}$ & NA & NA & - \\
\hline & Transportation classes $1-2$ & 3,200 & density & - & Transportation classes $1-2$ & 564 & decay & + \\
\hline & Transportation classes 4-5 & 1,500 & density & + & Transportation classes $4-5$ & 564 & density & + \\
\hline \multirow[t]{9}{*}{ Northeast } & Agriculture non-irrigated land & 6,400 & mean & - & Agriculture non-irrigated land & 564 & decay & + \\
\hline & USGS all sagebrush & 6,400 & mean & + & USGS all sagebrush & 564 & mean & + \\
\hline & USGS all sagebrush & 6,400 & $\begin{array}{l}\text { standard } \\
\text { deviation }\end{array}$ & + & USGS all sagebrush & 564 & $\begin{array}{l}\text { standard } \\
\text { deviation }\end{array}$ & + \\
\hline & ReGAP forested land & 3,200 & mean & - & ReGAP forested land & 564 & decay & + \\
\hline & MODIS NDVI & NA & NA & - & MODIS NDVI & NA & NA & - \\
\hline & Transportation classes $1-2$ & 3,200 & decay & + & Transportation classes $1-2$ & 564 & decay & + \\
\hline & Transportation classes $4-5$ & 1,500 & density & + & Transportation classes $4-5$ & 564 & density & + \\
\hline & & & & & USGS shrub height & 45 & mean & + \\
\hline & & & & & USGS shrub height & 45 & $\begin{array}{l}\text { standard } \\
\text { deviation }\end{array}$ & + \\
\hline \multirow[t]{8}{*}{ Central } & Agriculture non-irrigated land & 6,400 & decay & + & & & & \\
\hline & USGS all sagebrush & 6,400 & mean & + & USGS all sagebrush & 45 & mean & + \\
\hline & USGS all sagebrush & 6,400 & $\begin{array}{c}\text { standard } \\
\text { deviation }\end{array}$ & + & & & & \\
\hline & USGS herbaceous & 6,400 & mean & - & USGS herbaceous & 564 & mean & - \\
\hline & 1971-2000 normals ppt & 3,200 & mean & + & 1971-2000 normals ppt & 564 & mean & + \\
\hline & $\begin{array}{l}\text { 1971-2000 normals ppt } \\
\text { (quadratic) }\end{array}$ & 3,200 & mean & - & $\begin{array}{l}\text { 1971-2000 normals ppt } \\
\text { (quadratic) }\end{array}$ & 564 & mean & - \\
\hline & Transportation classes $1-2$ & 3,200 & density & - & Transportation classes $1-2$ & 564 & decay & + \\
\hline & Transportation classes 4-5 & 1,500 & density & + & & & & \\
\hline
\end{tabular}


Table 5. GIS data inputs for $A$, sage-grouse nesting, $B$, late brood-rearing summer, and $C$, winter models.-Continued

[USGS, U.S. Geological Survey; SB, sagebrush; NA, not applicable; ppt, precipitation; MODIS NDVI, Moderate Resolution Imaging Spectroradiometer Normalized Difference Vegetation Index; ReGAP, Regional National Gap Analysis Program]

\begin{tabular}{|c|c|c|c|c|c|c|c|c|}
\hline Region & Landscape predictor & $\begin{array}{l}\text { Kernel } \\
\text { radius } \\
\text { (meters) }\end{array}$ & $\begin{array}{l}\text { Summary } \\
\text { statistic }\end{array}$ & Association & $\begin{array}{l}\text { Patch } \\
\text { predictor }\end{array}$ & $\begin{array}{l}\text { Kernel } \\
\text { radius } \\
\text { (meters) }\end{array}$ & $\begin{array}{l}\text { Summary } \\
\text { statistic }\end{array}$ & Association \\
\hline \multirow{12}{*}{ Southwest } & \multirow[t]{3}{*}{ Terrain ruggedness } & \multirow[t]{3}{*}{1,500} & \multirow[t]{3}{*}{ NA } & \multirow[t]{3}{*}{-} & Terrain ruggedness & 564 & \multirow{3}{*}{$\begin{array}{c}\text { NA } \\
\text { standard } \\
\text { deviation } \\
\text { decay }\end{array}$} & \multirow{3}{*}{$\begin{array}{l}- \\
+\end{array}$} \\
\hline & & & & & USGS herbaceous & 564 & & \\
\hline & & & & & ReGAP forested land & 564 & & \\
\hline & Agriculture non-irrigated land & NA & Euclidean & + & & & & \\
\hline & USGS all sagebrush & 3,200 & mean & + & USGS all sagebrush & 45 & mean & + \\
\hline & USGS all sagebrush & 3,200 & standard & + & USGS all sagebrush & 45 & standard & - \\
\hline & & & deviation & & & & deviation & \\
\hline & ReGAP forested land & 3,200 & mean & - & ReGAP forested land & 564 & mean & - \\
\hline & $1971-2000$ normals ppt & 1,500 & mean & + & $1971-2000$ normals ppt & NA & NA & + \\
\hline & $\begin{array}{l}\text { 1971-2000 normals ppt } \\
\text { (quadratic) }\end{array}$ & 1,500 & mean & - & $\begin{array}{l}\text { 1971-2000 normals ppt } \\
\text { (quadratic) }\end{array}$ & NA & NA & - \\
\hline & \multirow[t]{2}{*}{ Terrain ruggedness } & \multirow[t]{2}{*}{1,500} & \multirow[t]{2}{*}{ NA } & \multirow[t]{2}{*}{-} & Terrain ruggedness & 564 & NA & - \\
\hline & & & & & MODIS NDVI & NA & NA & + \\
\hline \multicolumn{9}{|c|}{ C Winter models } \\
\hline \multirow[t]{8}{*}{ State } & $\begin{array}{l}\text { All agriculture land } \\
\quad \text { (irrigated and non-irrigated) }\end{array}$ & 3,200 & decay & + & $\begin{array}{l}\text { All agriculture land } \\
\quad \text { (irrigated and non-irrigated) }\end{array}$ & 564 & decay & + \\
\hline & USGS all sagebrush & 6,400 & mean & + & USGS all sagebrush & 564 & mean & + \\
\hline & USGS all sagebrush & 6,400 & standard & + & & & & \\
\hline & ReGAP forested land & 1,500 & $\begin{array}{c}\text { deviation } \\
\text { decay }\end{array}$ & + & ReGAP forested land & 564 & decay & + \\
\hline & Transportation classes $1-2$ & 1,500 & decay & + & Transportation classes $1-2$ & 564 & decay & + \\
\hline & Terrain ruggedness & 1,500 & NA & - & Terrain ruggedness & 564 & NA & - \\
\hline & \multirow[t]{2}{*}{2008 oil and gas well locations } & \multirow[t]{2}{*}{6,400} & \multirow[t]{2}{*}{ density } & \multirow[t]{2}{*}{-} & 2008 oil and gas well locations & 564 & density & - \\
\hline & & & & & USGS shrub height & 564 & mean & - \\
\hline \multirow[t]{5}{*}{ Northeast } & $\begin{array}{l}\text { All agriculture land } \\
\quad \text { (irrigated and non-irrigated) }\end{array}$ & 6,400 & mean & - & $\begin{array}{l}\text { All agriculture land } \\
\text { (irrigated and non-irrigated) }\end{array}$ & 564 & decay & + \\
\hline & USGS all sagebrush & 3,200 & mean & + & USGS all sagebrush & 564 & mean & + \\
\hline & ReGAP forested land & 3,200 & mean & - & ReGAP forested land & 564 & decay & + \\
\hline & Transportation classes $1-2$ & 3,200 & decay & + & Transportation classes $1-2$ & 564 & decay & + \\
\hline & Terrain ruggedness & 1,500 & NA & - & Terrain ruggedness & 564 & NA & - \\
\hline \multirow[t]{5}{*}{ Central } & USGS all sagebrush & 6,400 & mean & + & USGS all sagebrush & 564 & mean & + \\
\hline & USGS sagebrush (quadratic) & 6,400 & mean & - & & & & \\
\hline & USGS shrub height & 6,400 & mean & - & & & & \\
\hline & USGS shrub height & 6,400 & $\begin{array}{l}\text { standard } \\
\text { deviation }\end{array}$ & - & & & & \\
\hline & Terrain ruggedness & 5,64 & NA & - & Terrain ruggedness & 564 & NA & - \\
\hline \multirow[t]{6}{*}{ Southwest } & USGS all sagebrush & 6,400 & mean & + & & & & \\
\hline & USGS all sagebrush & 6,400 & standard & - & & & & \\
\hline & ReGAP forested land & 1,500 & $\begin{array}{c}\text { deviation } \\
\text { decay }\end{array}$ & + & ReGAP forested land & 564 & decay & + \\
\hline & Transportation classes $1-2$ & 1,500 & decay & + & Transportation classes $1-2$ & 564 & decay & + \\
\hline & Terrain ruggedness & 1,500 & NA & - & Terrain ruggedness & 564 & NA & - \\
\hline & 2008 oil and gas well locations & 1,500 & density & - & 2008 oil and gas well locations & 564 & density & - \\
\hline
\end{tabular}

patch, and combined landscape-patch), and multi-region models while using one-to-many hierarchical management boundaries. One-to-many hierarchical management boundaries is the result of the user specifying one or multiple management boundaries in the software. If the user specifies multiple overlapping boundaries, the tool collapses these into a single data use (that is, applies a union), and the software then summarizes and reports the habitat between all combinations of polygons resulting from the union process. The second tool (Habitat Model Selection Tool) allows land managers to assess local habitats using new sage-grouse observation data and existing habitat models. Both tools use Python scripts; therefore, users can update or modify these tools as needed.
When users specify input data (for example, telemetry locational data for the Habitat Model Selection Tool or polygonal data for the Habitat Summary Tool), the map projection for these inputs must match the map projections used for the sagegrouse habitat models. Because the map projection for the sage-grouse habitat models was developed using a custom definition, the easiest approach for assigning this map projection to data inputs is for the user to use ESRI and import the map projection from a sage-grouse habitat model. The approach for importing the map projection varies slightly by ESRI software versions, and the user can refer to ESRI documentation for a description of this process if required. 
Table 6. Description, data source, and spatial/temporal scales that apply to the GIS data inputs.

[m, meters; WYGISC, Wyoming Geographic Information Center; NAIP, National Agriculture Imagery Program; DEM, Digital Elevation Model]

\begin{tabular}{|c|c|c|c|c|c|}
\hline \multicolumn{2}{|c|}{ Model Predictor } & \multicolumn{2}{|l|}{ Source Data Characteristics } & \multirow{2}{*}{$\begin{array}{l}\text { Spatial } \\
\text { resolution } \\
\text { (meters) }\end{array}$} & \multirow[b]{2}{*}{$\begin{array}{l}\text { Ground } \\
\text { time-stamp }\end{array}$} \\
\hline $\begin{array}{l}\text { Model predictor } \\
\text { description }\end{array}$ & Subcategory & $\begin{array}{c}\text { Source } \\
\text { description }\end{array}$ & $\begin{array}{l}\text { Spatial } \\
\text { scale }\end{array}$ & & \\
\hline Agriculture Land & Irrigated & Wyoming Water Development Commission (WWDC; http://waterplan.state.wy.us) & $1: 24 \mathrm{~K}$ & & 2009 \\
\hline Agriculture Land & Irrigated & Powder River Basin (Doherty 2008). Digitized from $1 \mathrm{~m}$ NAIP and 25m Pan sharpened SPOT 5 & $1: 4 \mathrm{~K}$ & & 2003-2004 \\
\hline Agriculture Land & Non-irrigated & WYGISC (http://www.uwyo.edu/wygisc) & $1: 58,200 \mathrm{~K}$ & & 1980-1982 \\
\hline USGS Sagebrush & All products & USGS EROS (Homer et al. 2012; https://www.sciencebase.gov/catalog/folder/51366cfbe4b0338f3fc4cbd1) & $1: 24 \mathrm{~K}$ & 30 & 2006-2007 \\
\hline $\operatorname{ReGAP}^{1}$ & & Northwest ReGAP (http://gap.uidaho.edu/index.php/landcover) & $\begin{array}{l}1: 100 \mathrm{~K} \\
\text { minimum } \\
\text { mapping } \\
\text { unit: } 1 \text { ha }\end{array}$ & 30 & 1999-2001 \\
\hline Hydrology & Waterbodies $^{2}$ and flowline ${ }^{3}$ & High Resolution National Hydrologic Dataset (http://nhd.usgs.gov/data.html) & $1: 24 \mathrm{~K}$ & & $\begin{array}{c}\text { Downloaded } \\
\text { on } 06 / 29 / 2009\end{array}$ \\
\hline Transportation $^{4}$ & & $\begin{array}{l}\text { Interim transportation data set with unknown accuracies (spatial and aspatial), but significantly better } \\
\text { than Census Tiger }\end{array}$ & $1: 24 \mathrm{~K}$ & & Est. 2009 \\
\hline Oil and Gas Locations & & Wyoming Oil and Gas Conservation Commission (http://wogcc.state.wy.us/) & Est. 1:100K & & $\begin{array}{l}\text { Represents all } \\
\text { active oil and } \\
\text { gas as of } 2008\end{array}$ \\
\hline Climate Normals & $\begin{array}{l}\text { Total monthly precipitation } \\
\text { across all months ( } 30 \text { year } \\
\text { climatological average of } \\
\text { annual precipitation in } \mathrm{mm}\end{array}$ & $\begin{array}{l}\text { Oregon State University (http://www.prism.oregonstate.edu/) and Climate Source Inc., Climate } \\
\text { Normals (http://www.climatesource.com/); Data cannot be distributed. }\end{array}$ & & $\begin{array}{l}400 \\
\text { resampled } \\
\text { to } 30\end{array}$ & 1971-2000 \\
\hline $\begin{array}{l}\text { Normalized Difference } \\
\text { Vegetation Index } \\
\text { (NDVI) }\end{array}$ & $\begin{array}{l}\text { Version-5 MODerate-resolution } \\
\text { Imaging Spectroradiometer } \\
\text { (MODIS) }\end{array}$ & $\begin{array}{l}\text { Product mod13q1, } 16 \text { day composite (Land Processes Distributed Active Archive Center (LPDAAC); } \\
\text { https://lpdaac.usgs.gov/get_data/data_pool) }\end{array}$ & & $\begin{array}{l}250, \\
\text { resampled } \\
\text { to } 30\end{array}$ & $\begin{array}{l}\text { 2004, Julian } \\
\text { date 225 (ending } \\
\text { August 12) }\end{array}$ \\
\hline Terrain Ruggedness & National Elevation Data (NED) & $\begin{array}{l}\text { Developed statewide Digital Elevation Model (DEM) using NED (http://gisdata.usgs.gov/) and } \\
\text { derived the terrain ruggedness from the DEM (Sappington et al., 2007). Ruggedness distinguishes } \\
\text { between steep and even terrain (high slope and low ruggedness) versus steep uneven terrain (high } \\
\text { slope and high ruggedness). }\end{array}$ & & 30 & $\begin{array}{l}\text { Downloaded } \\
06 / 26 / 2009\end{array}$ \\
\hline
\end{tabular}

${ }^{1}$ Refer to Table 6 on data classification scheme.

${ }^{2}$ Refer to Table 7 on data classification scheme.

${ }^{3}$ Refer to Table 8 on data classification scheme.

${ }^{4}$ Refer to Table 9 on data classification scheme. 
Table 7. Descriptions of vegetation classes used for GIS data inputs.

[ReGAP VALUE and ESLF-NLCD_CODE columns relate to attribute columns defined in the GIS data for anyone wanting to investigate these data]

\begin{tabular}{|c|c|c|}
\hline ReGAP VALUE & ESLF-NLCD_CODE & Description \\
\hline \multicolumn{3}{|r|}{ Forest } \\
\hline 66 & 4233 & Northern Rocky Mountain Subalpine Woodland and Parkland \\
\hline 69 & 4237 & Rocky Mountain Lodgepole Pine Forest \\
\hline 70 & 4238 & Southern Rocky Mountian Dry-Mesic Montane Mixed Conifer Forest and Woodland \\
\hline 72 & 4241 & Southern Rocky Mountain Ponderosa Pine \\
\hline 77 & 4266 & Middle Rocky Mountain Montane Douglas-fir Forest and Woodland \\
\hline 78 & 4267 & Rocky Mountain Poor Site Lodgepole Pine Forest \\
\hline 84 & 4302 & Inter-Mountain Basins Aspen Mixed Conifer Forest-Woodland \\
\hline 85 & 4303 & Inter-Mountain Basins Mountain Mahogany Woodland and Shrubland \\
\hline 114 & 5426 & Northern Rocky Mountain Foothill Conifer Wooded Steppe \\
\hline 144 & 8401 & Introduced Upland Vegetation - Treed \\
\hline 72 & 4241 & Southern Rocky Mountain Ponderosa Pine \\
\hline 73 & 4242 & Rocky Mountain Subalpine Dry-Mesic Spruce-Fir Forest and Woodland \\
\hline 74 & 4243 & Rocky Mountain Subalpine Mesic Spruce-Fir Forest and Woodland \\
\hline 77 & 4266 & Middle Rocky Mountain Montane Douglas-fir Forest and Woodland \\
\hline 78 & 4267 & Rocky Mountain Poor Site Lodgepole Pine Forest \\
\hline 114 & 5426 & Northern Rocky Mountain Foothill Conifer Wooded Steppe \\
\hline \multicolumn{3}{|r|}{ Riparian } \\
\hline 149 & 8480 & Introduced Riparian Vegetation \\
\hline 150 & 8490 & Introduced Wetland Vegetation \\
\hline 164 & 9155 & Northern Rocky Mountain Lower Montane Riparian Woodland and Shrubland \\
\hline 171 & 9171 & Rocky Mountain Subalpine-Montane Riparian Woodland \\
\hline 173 & 9187 & Rocky Mountain Subalpine-Montane Riparian Shrubland \\
\hline 177 & 9218 & Western Great Plains Open Freshwater Depression Wetland \\
\hline
\end{tabular}

\section{Habitat Summary Tool (Description and Usage)}

The habitat summary tool is designed to apply the U.S. Geological Survey sage-grouse seasonal models presented in this report. Because each seasonal model was developed using statewide and regional sage-grouse telemetry data, with predictions provided at the statewide extent, quantifying habitat occurrence may be cumbersome for some potential users. Thus, the objective of this tool is to allow non-GIS experts the ability to easily summarize habitat across multiple seasons, regions, and scales (that is, zonal statistics) within a specified area and then provide the user with Microsoft ${ }^{\circledR}$ Excel spreadsheets and graphs capturing the results. This tool assists users working with all the different models by calculating and reporting the quantity of habitat that exists within each feature defined by a specified area of interest and defined by the model selected by the user.
The graphical user interface (fig. 7) allows the user to specify the zones (that is, area of interest) for summarizing habitat area, the type of regional analysis (STATEWIDE, SOUTHWEST, CENTRAL, NORTHEAST, and REGIONAL), sagegrouse life-stage (NEST, SUMMER, WINTER), and the scale of the model (LANDSCAPE, PATCH, and combined landscape-patch $[\mathrm{L} \times \mathrm{P}])$. As mentioned earlier, the STATEWIDE, SOUTHWEST, CENTRAL, and NORTHEAST tool parameters allow the user to summarize a specific regional model across the entire state. The REGIONAL tool parameter uses the merged regional data and allows the user to summarize habitat within polygons across the state using the appropriate regional model underlining the polygons represented by the management boundary data set. Therefore, users can evaluate models applied to the individual region (for example, southwest evaluated for the southwest region and not for the central or northeast) or across regions (for example, southwest model evaluated in the 
Table 8. Descriptions of hydrologic water body (areal features) classes used for GIS data inputs.

[NHD, National Hydrologic Data; FCode relates to an attribute column defined in the GIS data for anyone wanting to investigate these data]

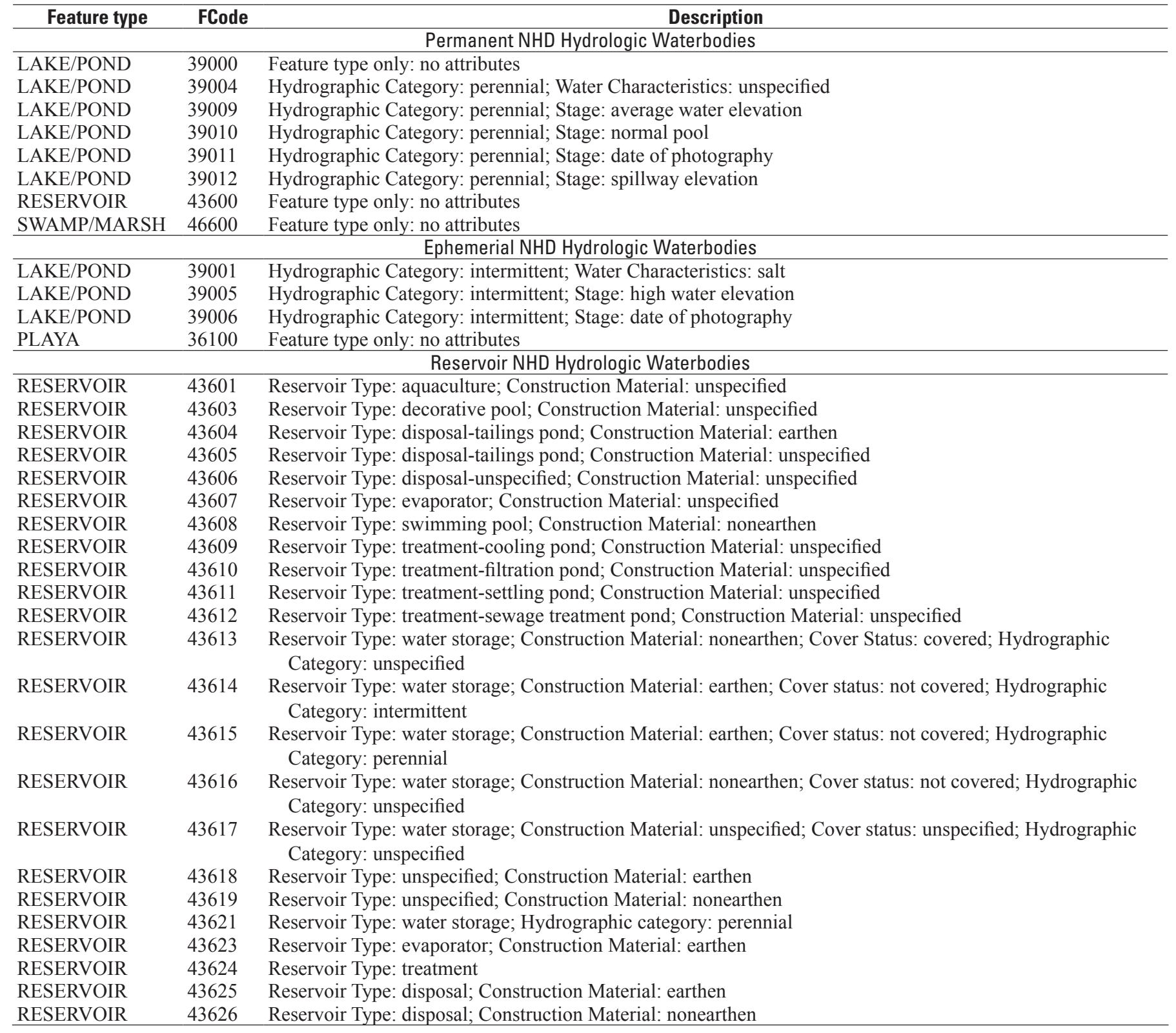

Table 9. Descriptions of hydrologic water flow (linear features) classes used for GIS data inputs.

[NHD, National Hydrologic Data; FCode relates to an attribute column defined in the GIS data for anyone wanting to investigate these data]

\begin{tabular}{lcc}
\hline \multicolumn{1}{c}{ Feature type } & FCode & Description \\
\hline & & Permanent NHD Hydrologic Flowlines \\
\hline ARTIFICIAL PATH & 55800 & Feature type only: no attributes \\
COASTLINE & 56600 & Feature type only: no attributes \\
CONNECTOR & 33400 & Feature type only: no attributes \\
STREAM/RIVER & 46000 & Feature type only: no attributes \\
STREAM/RIVER & 46006 & Hydrographic Category: perennial; Positional Accuracy: not applicable \\
\hline & 33600 & Ephemerial NHD Hydrologic Flowlines \\
\hline CANAL/DITCH & 33601 & Feature type only: no attributes \\
CANAL/DITCH & Canal/Ditch Type: aqueduct \\
CANAL/DITCH & 43602 & Canal/Ditch Type: unspecified \\
STREAM/RIVER & 46003 & Hydrographic Category: intermittent; Positional Accuracy: not applicable \\
STREAM/RIVER & 46007 & Hydrographic Category: ephemeral; Positional Accuracy: not applicable \\
\hline
\end{tabular}


Table 10. Descriptions of transportation classes used for GIS data inputs.

[DLG, Digital Line Graph]

\begin{tabular}{|c|c|c|}
\hline Category & Description & DLG code \\
\hline \multirow[t]{3}{*}{ Class 1} & Primary route, class 1 , symbol undivided & 1700201 \\
\hline & Primary route, class 1 , divided, lanes separated & 1700203 \\
\hline & Ramp in interchange (cloverleaf or interchange) & 1700402 \\
\hline Class 2 & Secondary route, class 2 , symbol undivided & 1700205 \\
\hline Class 3 & $\begin{array}{l}\text { Road, class 3, symbol undivided (road or street, } \\
\text { class 3) }\end{array}$ & 1700209 \\
\hline Class 4 & Road, class 4 (Road or street, class 4$)$ & 1700210 \\
\hline Class 5 & $\begin{array}{l}\text { Trail (class 5, other than four-wheel drive vehicle); } \\
\text { primarily two track }\end{array}$ & 1700211 \\
\hline
\end{tabular}

central and northeast regions). The first scenario exemplifies a basic user application while the second scenario exemplifies an advanced user application. The user provides one or many polygon feature classes (Area of Interest, AOI), where a feature class represents a vector data set with one to many polygons, and the tool produces a summary of the sage-grouse habitat area identified within the model, confined to the AOI. This tool uses the binned habitat models, but it produces results from the Boolean models as well. Although a minor distinction, this behavior of the tool does not affect the returned results. Therefore, if a user updates any of the data sources, they need to understand that the tool uses the binned habitat models to generate both the binned and Boolean results. The tool does not summarize RSF models, because the RSF values are not directly comparable until a thresholding approach is applied.
If the user provides multiple AOIs (for example, allotments within a management zone), a union analysis is applied to these AOIs, and all polygons within each specified data set are combined into a single data set. Any overlapping polygons result in a union of those polygons (see ESRI documentation for additional details). This method summarizes the total amount of habitat area within each resulting polygon. Because multiple input AOIs are allowed, a unique identifier is assigned to each spatial feature with a value of "Zone 1" to "Zone N," where $\mathrm{N}$ equals the sample size or total of all resulting polygons. Since ESRI's zonal statistics tool does not handle overlapping polygons within a zonal data set, our tool does not handle these scenarios either. However, our tool does allow users to specify multiple zonal data sets with overlapping polygons, but overlapping polygons within a single data set are ignored by ESRI. If users would like to evaluate a single data set with areas of overlapping polygons, they can extract out all overlapping features, store the overlapping features in independent data sets, and then use these independent data sets as the tool inputs. This tool clips all vector data to the extent of the models before any analysis, since all analysis is confined to the sage-grouse habitat model extents.

The Habitat Summary Tool allows users to investigate the models in a variety of applications; therefore, the tool lends itself to flexibility and analysis of the models. The tool will correctly handle the habitat summaries across the different regions (if REGIONAL is specified as a tool parameter) or

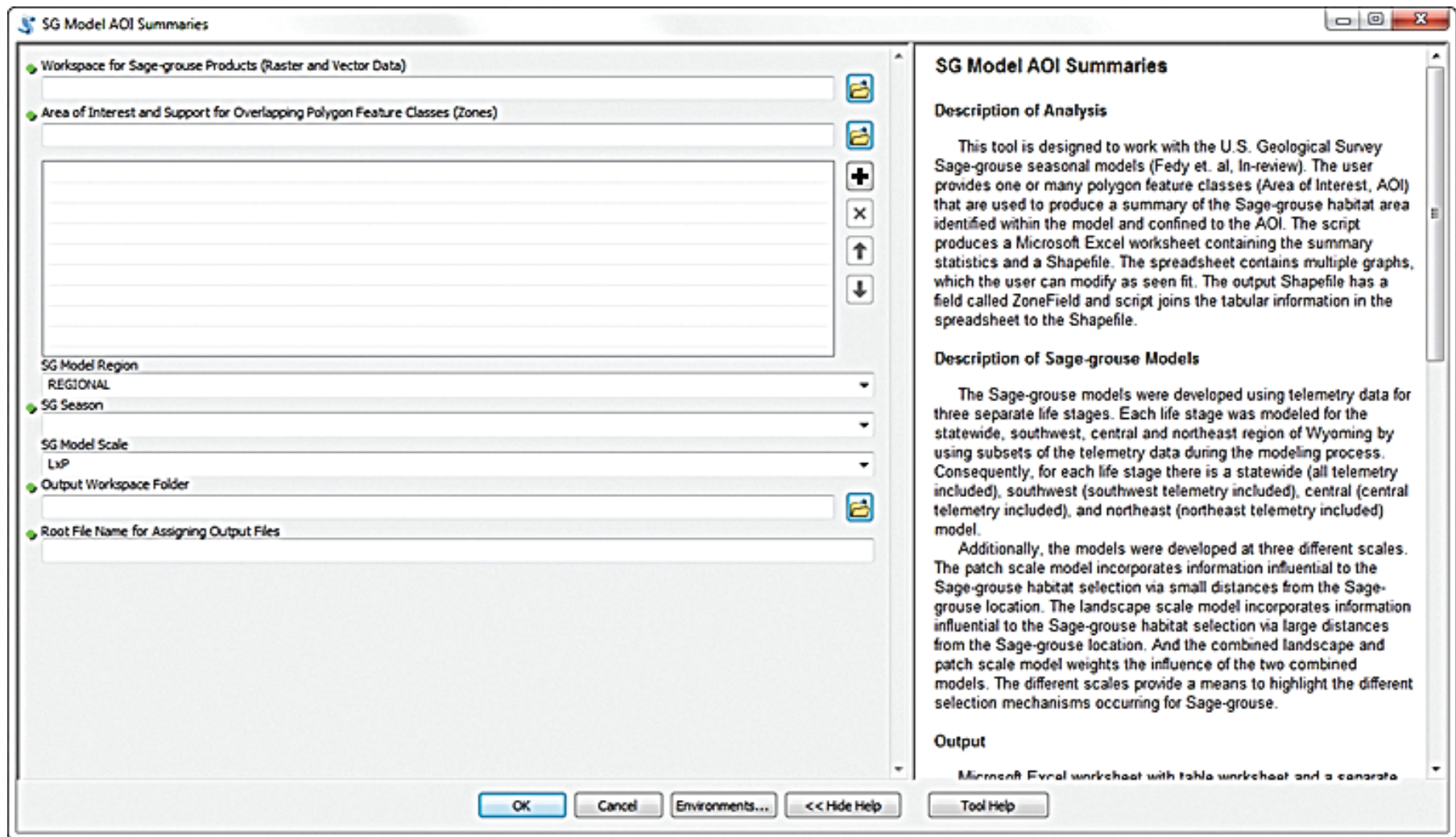

Figure 7. Graphical user interface of the Habitat Summary Tool. 
allow the user to evaluate a specific regional model in a different region. The purpose of this tool is to allow users to explore the models with minimal constraints and GIS expertise. In most cases, users will select their life-stage, $\mathrm{L} \times \mathrm{P}$ scale, and REGIONAL parameters and then assess the results.

The tool produces an ESRI Shapefile and Microsoft Excel spreadsheet. The Shapefile contains a primary key (ZonalField) that is also included in the spreadsheet, thereby allowing users to generate cartographic figures of the results. Worksheet 1 (TabularResults) provides the aspatial results from the analyses. The second worksheet (Graphs) contains four graphs characterizing the area and percent area of binned habitat within each management polygon and the area and percent area using the Boolean data within each polygon. The third worksheet (Definitions) defines the fields used in the TabularResults worksheet (the field definitions are also provided in the help documentation). Two of the graphs represent habitat area by zone (fig. $8 \mathrm{~A}$ and $8 C$ ) and the other two graphs represent percent area by zone (fig. $8 B$ and $8 D$ ). For example, if your zones represent sage-grouse core areas, the graphs illustrate the 'percentage' and 'area' of non-habitat, "less probability" of habitat, 'more probability' of habitat, and 'highest probability' of habitat occurring within each unique sage-grouse core area. Users can manipulate these graphs or create new graphs using data located in TabularResults.

Users will need to crosswalk between the unique identifier (ZoneField) in the Shapefile and the spreadsheet data (TabularResults) because the $\mathrm{x}$-axis in the graphs produced in the spreadsheet lack meaningful labels. We did not label the graphs based on polygon names because these descriptions can be long. It can also be difficult to programmatically generate meaningful titles within the software. However, the user can simply change the first column of the data spreadsheet (TabularResults) to reflect the names they would like to use, and the graphs will automatically update. Unless the sagegrouse model's coordinate system is changed, the area units represented within the graphs are meters squared. We considered producing the output of this tool in many forms (for example, HTML and Python Matplotlib $\left.{ }^{\circledR}\right)$, but we decided to use Microsoft Excel and a Shapefile because these should allow most users to easily manipulate the graphs and use the data as desired.

As a technical note, The "SG Model AOI Summaries" tool must run in the foreground within ArcCatalog because it uses the PyWin32 Python library, which is available for 32-bit architecture only. This library is used for processing Microsoft Excel files. The deployment of this tool correctly sets up foreground geoprocessing (an ESRI option that a user can change for toolbox scripts). Although the user has the capability of changing this parameter, the tool will not function correctly because the Python module installed with the toolbox is not available for 64-bit architectures. See ESRI documentation for how 32-bit and 64-bit geoprocessing function in ArcGIS Desktop 10.1 (service pack 1) and future releases.

\section{Habitat Model Selection Tool (Description and Usage)}

We developed a second tool that determines which sagegrouse habitat model is providing the best predictions based on known sage-grouse locations occurring in novel areas. The seasonal sage-grouse models produced by Fedy and others (2014) used regional sage-grouse telemetry data to establish habitat-selection criteria. Therefore, the sage-grouse models reflect regional (southwest, central, and northeast) habitat characteristics indicated by those usage patterns. This tool can help users to assess local habitat-use patterns using newly collected sage-grouse telemetry data and existing regional habitat models. This type of application can provide insight into novel areas where sage-grouse telemetry data did not exist during original model development. In this manner, newly collected local sage-grouse telemetry data may be compared to habitat models developed using regional sage-grouse telemetry data. Therefore, the tool's results should prove useful to land managers because it can discern which new local sage-grouse studies benefit land managers' (and others) understanding of sage-grouse habitat selection by identifying areas the regional models did not capture. The tool's results will not properly evaluate the habitat models because of comparison of local data to a regional model. However, this information can assist land managers and researchers in making better-informed decisions, such as where to locate new sage-grouse studies, and how they might refine regional habitat definitions, thereby increasing their understanding and application of regional habitat-selection criteria.

The tool is not intended to evaluate sage-grouse data scattered across the state, but we do not restrict the analysis to a maximum spatial extent. We also do not prevent users from evaluating sage-grouse locational data within the study sites used for developing the models, but again, the tool is not designed for such analysis. This tool is aimed for users that are interested in evaluating the models in novel areas and who have an understanding of their study site and the models we have presented. The tool does not create new models, nor does it threshold RSF models, but rather the tool evaluates the individual Boolean landscape, patch, and combined landscapepatch model performance relative to newly collected local sage-grouse data. Users should recognize that this tool does not provide statistical measures of RSF model performance. Instead, the tool examines how well newly collected sagegrouse location data match the habitat described by each sagegrouse model. Users should also be cautious when interpreting these results because a model could be highlighted as the top model for the wrong reasons. For example, the tool does not evaluate the underlying model characteristics such as overestimation of habitat use, yet the tool would rank such a model better than a model with more discriminatory power.

If users are evaluating telemetry data with this tool, they will want to evaluate their data against the appropriate sage-grouse life-stage habitat model. For example, if their study was monitoring sage-grouse nesting, then they should examine these data with the sage-grouse habitat models. The 
Sage-grouse Seasonal Habitat Area by Class

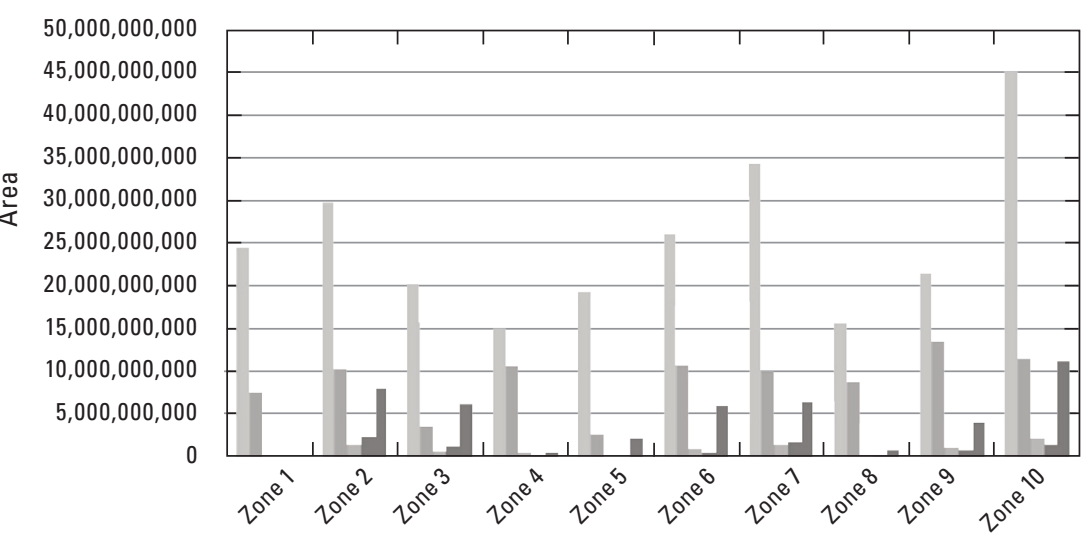

C Sage-grouse Seasonal Habitat Area by Class

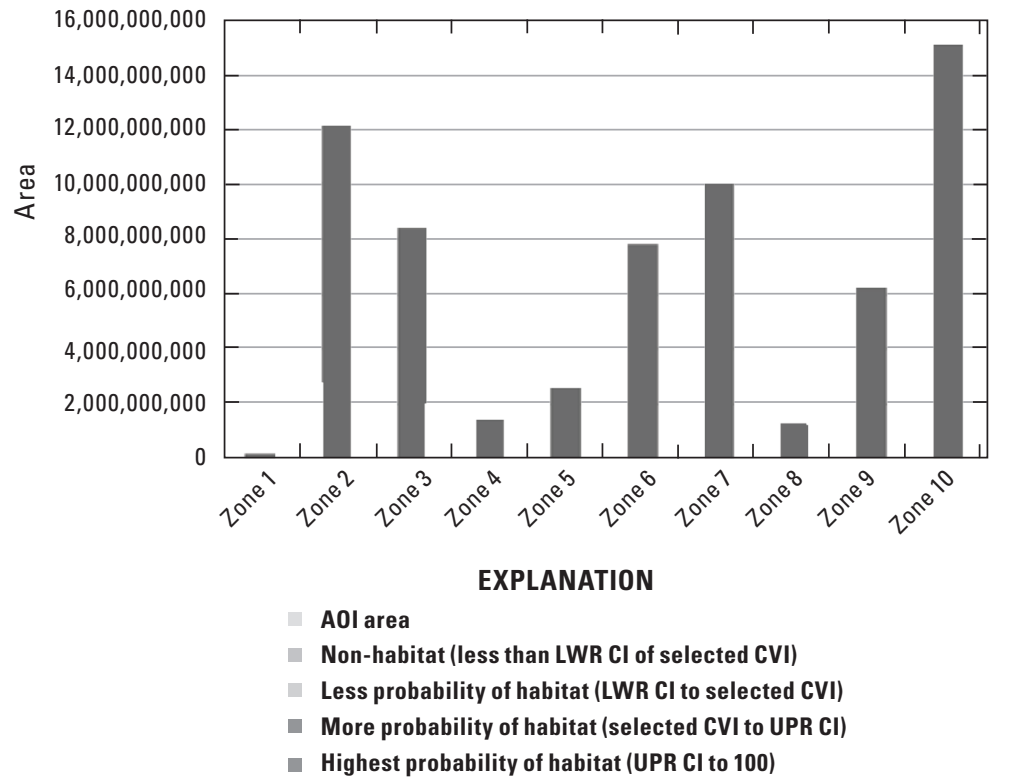

$B$

Sage-grouse Seasonal Habitat Percent Area by Class

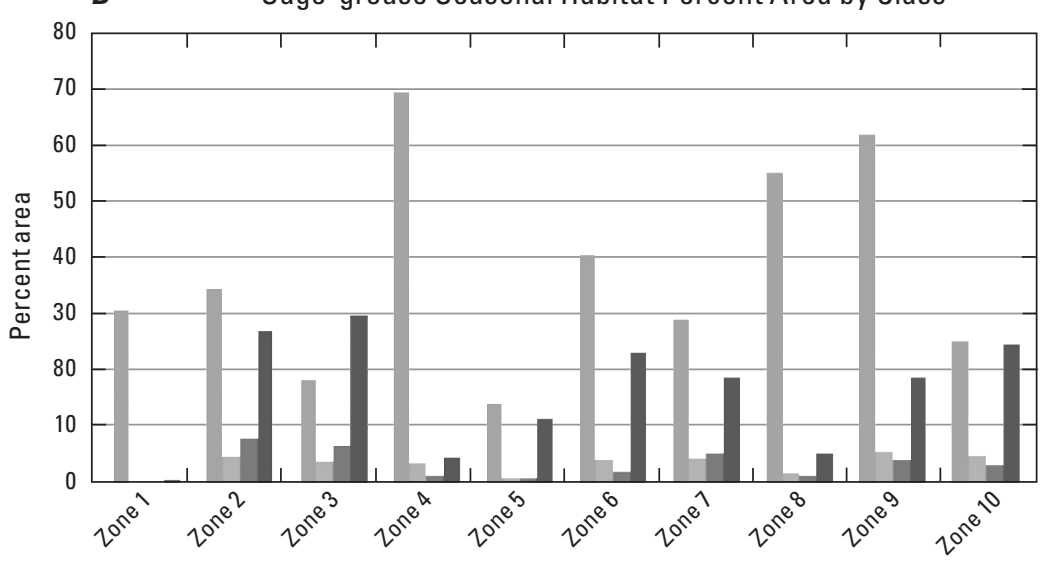

D Sage-grouse Seasonal Habitat Percent Area by Class

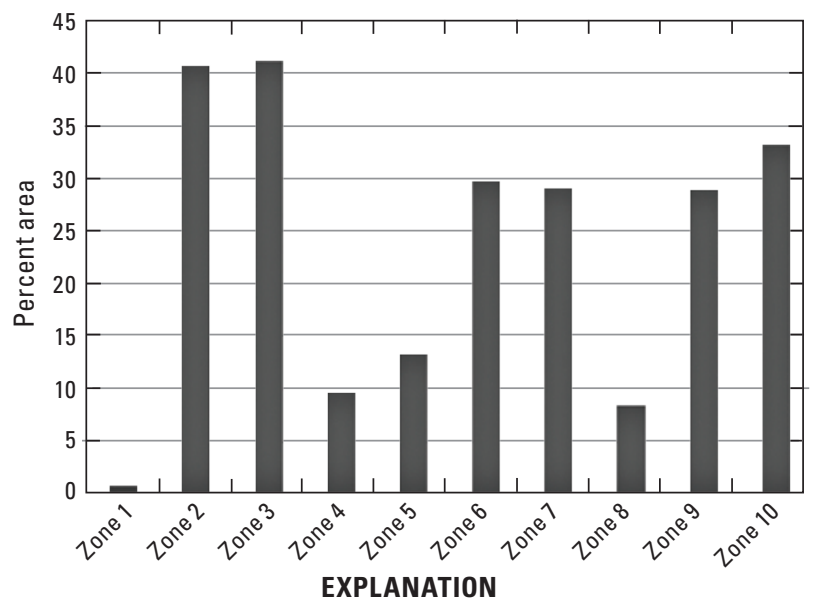

- Non-habitat (less than LWR CI of selected CVI)

- Less probability of habitat (LWR CI to selected CVI)

- More probability of habitat (selected CVI to UPR CI)

- Highest probability of habitat (UPR CI to 100)

Figure 8. Example of output graphs from the Habitat Summary Tool. Two of the graphs represent habitat area (squared meters) by zone (fig. $8 \mathrm{~A}$ and $8 \mathrm{C}$ ) and the other two graphs represent percent area by zone (fig. $8 B$ and $8 D$ ). 
habitat models contain some no-data pixels (no predictions of habitat), because masks existed in the sagebrush data products (Homer and others, 2012). As a result, any telemetry data located within these regions cannot be evaluated with the software. These masks usually pertain to higher elevations where Homer and others (2012) did not predict sagebrush, and in some cases, they masked areas that contained clouds.

To use the tool, the user specifies a point data set with known sage-grouse use locations for a particular season (lifestage) and executes the tool (fig. 9). The tool reports on how well each model (life-stage and region) captures the sagegrouse data within the predicted habitat. A table of summary statistics is created and displayed as HyperText Markup Language (HTML, fig. 9). We calculate the percent of locations captured/not captured within habitat; the minimum, maximum, average, and standard deviation of distances between locations and habitat; as well as the percent of locations captured within a set of distances $(0.0-0.5 \mathrm{~km}, 0.5-1 \mathrm{~km}, 1-2 \mathrm{~km}, 2-3 \mathrm{~km}$, 3-4 km, 4-5 km, 5-6 km, greater than $6 \mathrm{~km}$ ) between sagegrouse locations and the nearest predicted habitat. The user can use this information to decide which model (statewide, regional [southwest, central, and northeast], and scale [landscape, patch, and combined landscape-patch]) perform better with respect to known use locations. Combined with expert local knowledge and statistical results, one can decide which model they would like to use for estimating habitat distributions for their local region. One might also use the tool as a planning resource by distributing points of planned activities and determining which habitat life-stages are affected most by the proposed activities.

The Habitat Model Selection Tool will help land managers evaluate models for local accuracy using newly collected sage-grouse telemetry data. This process can be useful for investigating a number of questions:

- How do models perform in areas where models are not developed with telemetry data (that is, novel areas)?

- Which model is capturing the telemetry data best and how can this information be used to inform improvements to collecting additional sage-grouse data and (or) delineating more biologically relevant regions?

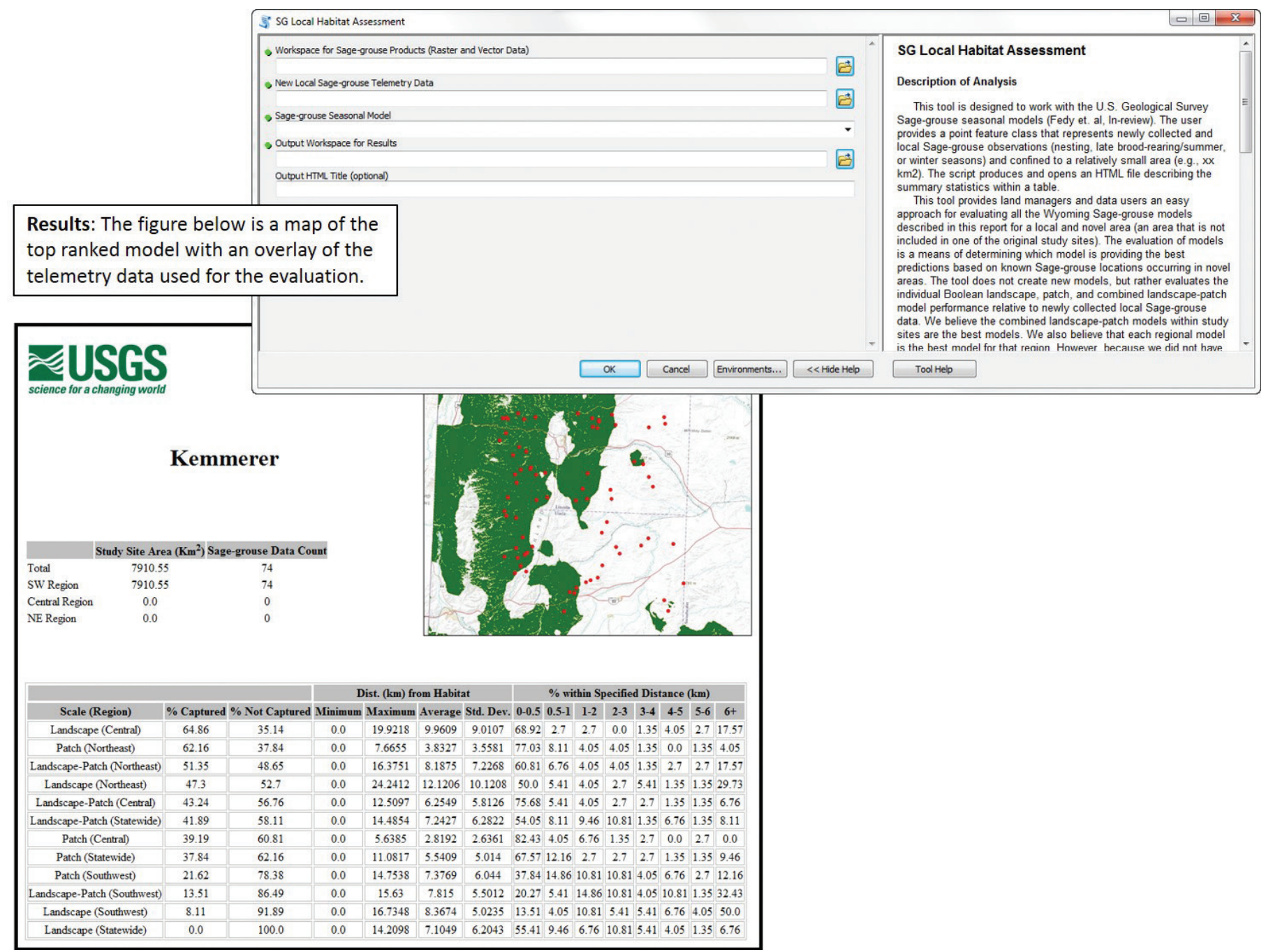

Figure 9. Graphical user interface and output from the Habitat Model Selection Tool. 
- Are there environmental conditions within the novel area that were excluded from the models that possibly influence the sage-grouse occupancy? (the GIS data may not have been available statewide, and data users can investigate both [1] the metadata and [2] Fedy and others, 2014)

- If a user creates new threshold data products, with minor modifications to the code, the user could evaluate performance of those changes using this tool.

Because the sage-grouse study sites were not designed for this statewide application, they do not represent a random sample of all sage-grouse habitat across the state. Thus, the combined landscape-patch models may not always produce the best results for novel areas (refer to Fedy and others, 2014). This tool will provide useful information about model performance in novel areas. For example, the tool might suggest whether additional study sites will enhance predictions within the novel area if models were developed using the additional study sites. The tool also can inform whether the models work outside the site availability extents. The tool does not develop new models, but it is useful for evaluating how well the models perform in novel areas and where focuses on new study sites could benefit the development of new habitat models. The analyses handled by these tools can also be executed using statistical software, but our objective was to provide a tool that was accessible to a larger audience.

\section{Resources}

The software-deployment packages, which we developed for several ArcGIS Desktop software releases (for example, $10.0,10.1$, and 10.2), allow users to work with different releases of ArcGIS Desktop. The need to produce a deployment for each version of ArcGIS Desktop is because the versions of Python used by ESRI vary, and our software uses a third-party Python module. We provide a list of software dependencies for these tools, installation instructions, and other pertinent information here.

\section{Software Dependencies (Not included in download)}

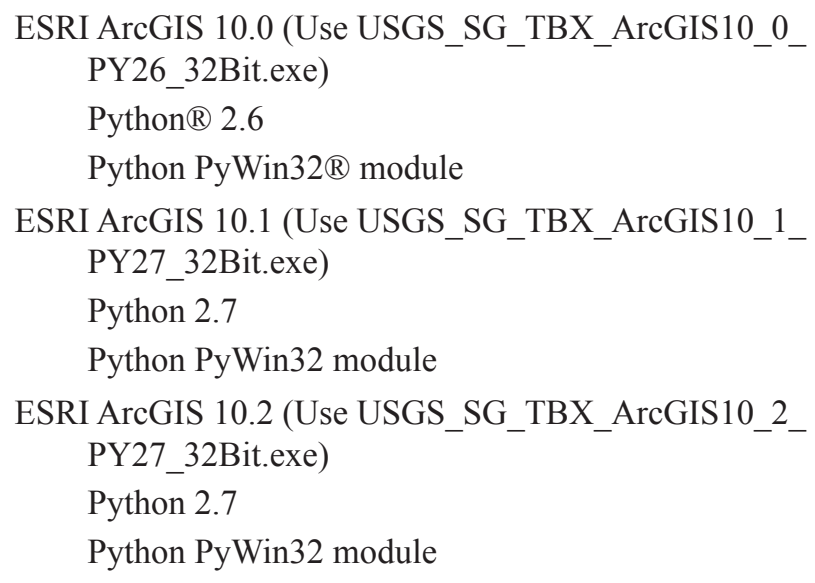

Wyoming sage-grouse habitat tools (source code) Source code of all software releases (USGS_SG_TBX_ ArcGIS_All.zip)

Spatial Analyst ${ }^{\circledR}$ extension and license (All releases require extension)

Microsoft ${ }^{\circledR}$ Excel (Habitat Summary Tool Only): Tested with .xls and .xlsx files

Web Browser (Habitat Selection Tool Only)

Due to differences in HTML standards of different web browsers, the image created and displayed in the output for the Habitat Selection Tool may not work correctly. We have tested numerous browsers, and, in one case, the browser version caused the image to not display correctly. The image is not critical to the analysis or interpretation of the results, and users have the option of installing a different web browser or examining their data and the top models in ESRI ArcMap. With this tool, Python selects the user's default web browser and opens the results. The default web browser is generally set by the user during the installation of the web browser (or installation of an operating system), but the user can change a web browser to their new default through the browser settings.

\section{Install Procedure}

1. Download all sage-grouse models described in the report (GIS Data Download) and refer to the required data structure shown in figure 10, which illustrates how to store the data products if working with the software.

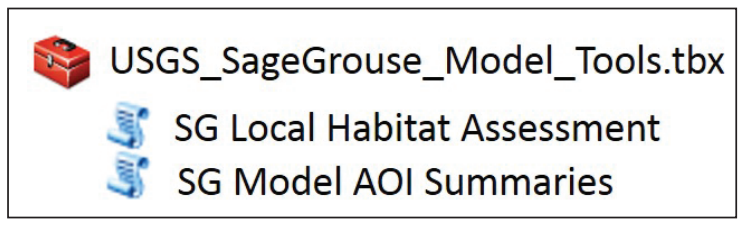

Figure 10. Required directory structure of downloaded data and software tools.

2. Download the appropriate installer based on the version of ESRI ArcGIS Desktop in use. Run the installer (executable), which will install PyWin32 module and install the ToolBox in ESRI InstallDir ToolBox location (for example, [InstallDir] \Desktop10.0\ArcToolBox\ Toolboxes). Removing or changing file contents that are installed on the machine will likely lead to failures with using these tools.

3. Verify that you are using the correct tool relative to the version of ESRI software and that your local system includes all software dependencies.

4. Read and agree to the PyWin32 Python module license agreement, which is a third party open source Python module included in our software deployment. 
5. Navigate to $\operatorname{ArcCatalog}^{\circledR}$ (fig. 10), add the toolbox, and you are ready to use the data products and the USGS ArcToolbox. The user can add the toolbox to ArcMap, ArcCatalog, or navigate to the toolbox through the ArcCatalog tree.

6. If the user wants to uninstall the software, navigate to the operating system control panel, locate the software, and then uninstall. The uninstall process will not remove the PyWin32 module (used often by Python developers on Microsoft Windows and therefore we do not install during this process); users can remove this module through the control panel if desired.

\section{Required Directory Structure}

After downloading the data and software, the user should store these files in a directory structure like the one provided in figure 11 in order for the software tools to correctly locate the data. The folder containing the ArcGIS ArcToolBox can reside anywhere, and the user should not alter its contents. The raster data sets should reside in a single folder, and the user should not alter the filenames or data. Within this folder, the ESRI File Geodatabase ${ }^{\circledR}$, which contains several feature classes used by the scripts, should also exist. The name of the File geodatabase should not change. If users prefer to set this up differently, they can modify the individual scripts tied to the ArcToolBox, but we cannot provide support for user modifications or enhancements.

\section{WorkspaceExample}

SpatialData

1. WY_SG_Seasonal_Deliverables.gdb
파f wysg_I_central_nest_bool.tif
- et Cetera.

Figure 11. Navigating to the toolbox from ArcCatalog.

\section{Help Documentation}

We provide documentation for the toolbox and the individual scripts attached to the toolbox. If the user clicks on the toolbox (mouse right-click) or any script attached to the ArcToolBox and selects "Help," they can view an HTML page of the tool's documentation. The user can also access the help documentation after they invoke a tool and select the Help button associated with the tool (Graphical User Interface [GUI]).

\section{Software Quality Assurance}

We ran several tests to ensure that these software tools produce expected results. The first and most obvious question about the tools is whether they provide accurate estimates. To test the Habitat Summary Tool, we used several different feature classes that represent AOIs and executed ESRI's geoprocessing tools (versus using the software we developed) using multiple combinations of model inputs (single region, statewide, and regional). We also tested the tool using the different life-stages and scales using ESRI geoprocessing tools. We then evaluated the output of these tests and compared them with results developed from the software described in this report. Because our software tools also rely on calculations not available in ESRI geoprocessing tools, we used hand calculations in these cases, and then verified that the manual approach produced the same results as our tool.

To test the results returned by the Habitat Model Selection Tool, we ran the tool on a set of data we received for this project that exist in a novel area. We determined that the statistical results returned by the GIS tool coincide with the results returned by running the same analyses in a statistical software package (StataCorp, 2007). We were also able to calculate these summary statistics by hand and verify the results. We did not evaluate multiple novel areas because we did not have data for these tests, but we do not anticipate errors resulting from using data in different locations. Because this tool generates output in HTML/CSS, we also tested whether different web browsers might have difficulties rendering the output. We did not find any problems while testing Chrome ${ }^{\circledR}$, FireFox Mozilla ${ }^{\circledR}$, and Microsoft ${ }^{\circledR}$ Internet Explorer, and we do not anticipate problems because the HTML/CSS code used with this tool is not dependent on different browser standards.

The next quality assurance tests we performed for these tools are whether they could operate on different workstations. We evaluated the tools on several workstations, but unfortunately, they all used Microsoft Windows 7 (versus Windows XP or another operating system). However, since these tools rely on Python and ESRI software, we do not anticipate this to be a shortfall for our quality assurance of these tools. Since these tools rely on third party Python modules, and because different versions of ESRI rely on different Python versions, the software releases should reflect Python/ESRI versioning. In other words, in the case of our software, the operating system (Windows XP versus Windows 7) should not affect the functionality of our software. Different operating systems can rely on different operating system service packs or other dependencies, which has the potential to affect using this software. For example, Microsoft made significant changes in security between Windows XP and Windows Vista/ Windows 7 , and this can affect the necessary methods to do certain tasks (for example, make registry edits or read/writes of files in certain locations of disk drive). These differences require software to handle tasks differently, and without testing, these can potentially lead to software not working. 


\section{Software Updates}

All updates to the software and sage-grouse models are contingent on future funding and need. Users are welcome to modify the software and (or) update the software to work with newer releases of ESRI software.

\section{Frequently Asked Questions}

So far, we have described the sage-grouse models, how different user needs can analyze the models, and different scenarios for making decisions using the data. In addition to these workflows, we provide a list of common questions and answers that relate to the appropriate use of the models, which should further aid new users.

1. Is the model sufficient to predict relative differences between alternative management scenarios (acreages) across the State of Wyoming?

The collection of models developed in the manuscript is one of the best available science-based tools to assess the relative differences between alternative management scenarios across the State of Wyoming.

2. Is the model sufficient to predict relative differences between alternative management scenarios (acreages and [or] delineations) across the Planning Area?

Yes, the models should be sufficient and relevant for use at the Planning Area scale.

3. Is the model sufficient to predict relative differences between alternative management scenarios across a field office?

Yes, the models should be sufficient and relevant for use in assessing the relative differences among alternative management scenarios across a field office in Wyoming.

4. Is the model sufficient to identify areas for future study (observation/verification)?

Yes, the models will be helpful in identifying areas for future sage-grouse research.

5. Is the model sufficient to support restrictions on land uses at a scale between 25 acres and 40 acres?

Unlikely. The models incorporate a combination of both landscape and patch scales and therefore small areas require on the ground assessments. For areas of 25-40 acres, individuals should supplement these data products with expert local knowledge of the area because the models are designed for landscape scale assessments. The real strength of these models is that they provide the landscape context (summary information of large areas) of the smaller spatial scale (for example, 40 acres) of interest.
6. Is the model sufficient to determine the exact locations to avoid or limit development (that is, placement of an oil or gas well, or a transmission line)?

No. However, the models could be a guide for an initial start. We suggest that a field assessment would also be required. Overall, we feel the models can be used effectively and efficiently for questions $1-4$. In some cases, we recommend the quantification of a range of habitat values within the specific area of interest using the confidence intervals (that is, fuzzy logic) rather than single absolute values. For questions 5 and 6 , we believe the models can be used for an initial assessment of development with respect to landscape-scale processes, but expert knowledge of local habitat conditions and use patterns is required for accurate recommendation or restrictions. We caution the use of these models for topics related to questions 5 and 6 because some models incorporate landscape scale metrics and the models include data inputs of varying map scales; however, the models could be used to provide the landscape context and as one piece of the decision making process.

7. How do I treat my assessment of habitat when the area straddles habitat and non-habitat?

First, recall that habitat assessments should not evaluate habitat conditions of small areas (for example, less than 40 acres). Second, recognize that for each pixel classified as habitat, the assigned value takes into consideration the condition (value) of neighboring pixels (adjacent landscape perspective). Therefore, hard boundaries of habitat and non-habitat will not exist and in all cases, expert knowledge is necessary for making these management decisions.

\section{Summary}

We have presented GIS data for three life-stages of Wyoming Greater Sage-grouse habitats, which were developed by Fedy and others (2014). In addition to the habitat models, we also provide vector GIS data sets of study area extents and the regional boundaries used for developing the models. With these data, land managers, conservationists, researchers, and wildlife enthusiasts, can thoroughly explore Wyoming Greater Sage-grouse habitats. We have also presented GIS software tools that will assist non-GIS experts with evaluating and using these habitat models. This suite of tools provides one of the best available resources of sage-grouse habitat products currently available for Wyoming, but users should not solely rely on these products. As with any model and tool, expert knowledge, auxiliary data, and field observations are highly recommended when making policy and land-management decisions. 


\section{Data and Software Disclaimer}

Although these data have been processed successfully on a computer system at the USGS, no warranty expressed or implied is made regarding the display or utility of the data on any other system, or for general or scientific purposes, nor shall the act of distribution constitute any such warranty. The USGS shall not be held liable for improper or incorrect use of the data described and (or) contained herein. Although this program has been used by USGS, no warranty, expressed or implied, is made by the USGS or the U.S. Government as to the accuracy and functioning of the program and related program material, nor shall the fact of distribution constitute any such warranty, and no responsibility is assumed by the USGS in connection therewith.

\section{Acknowledgments}

Funding for the synthesis of these studies and the conceptual development of these models and analyses was provided by Arch Coal, Cameco Resources, Devon Energy, Foundation Coal West, Pathfinder Energy, Petroleum Association, Powder River Coal, RioTinto, Rocky Mountain Power, Sage Grouse Local Working Groups, Wyoming Game and Fish Department (WGFD), Bureau of Land Management (BLM) and U.S. Fish and Wildlife Service, and the U.S. Geological Survey. We acknowledge the cooperation of numerous landowners in each study area who provided access to their private lands to collect field data. We also thank the many individuals who provided logistical and field support on the individual projects listed within data lineage.

Dr. David Gummer contributed significantly to the methods, specifically for the development and use of thresholding the RSF surfaces. This approach developed by David Gummer and Cameron Aldridge was applied using parallel computing software developed by Michael O'Donnell at the U.S. Geological Survey Fort Collins Science Center, but currently it is not available for public use.

\section{Telemetry Data Contributions}

- Jeffrey L. Beck, Department of Ecosystem Science and Management, University of Wyoming, Dept 3354, 1000 East University Ave., Laramie, WY 82071, USA.

- Bryan Bedrosian, Craighead Beringia South, PO Box 147, 6955 E. $3^{\text {rd }}$ St., Kelly, WY 83011, USA.

- Gregory D. Johnson, Western EcoSystems Technology, Inc., 2003 Central Avenue, Cheyenne, WY 82001, USA.

- Nicholas W. Kaczor, U.S. Fish and Wildlife Service, 134 Union Blvd., Suite 300, Lakewood, CO 80228, USA.
- Christopher P. Kirol, Department of Ecosystem Science and Management, University of Wyoming, Dept 3354, 1000 East University Ave., Laramie, WY 82071, USA.

- Cheryl A. Mandich, Department of Zoology and Physiology, University of Wyoming, Casper Center, 125 College Drive, Casper, WY 82601, USA.

- David Marshall, KC Harvey Environmental, LLC, 376 Gallatin Park Drive, Bozeman, MT 59715, USA.

- Gwyn McKee, Thunderbird Wildlife Consulting, Inc., 5303 Van Ripper St., Gillette, WY 82718, USA.

- Chad Olson, Hayden-Wing Associates, LLC., 2308 South $8^{\text {th }}$ Street, Laramie, WY 82070, USA.

- Aaron C. Pratt, Department of Ecosystem Science and Management, University of Wyoming, Dept 3354, 1000 East University Ave., Laramie, WY 82071, USA.

- Christopher C. Swanson, Kulm Wetland Management District, U.S. Fish and Wildlife Service, Kulm, ND 58456, USA.

- Brett L. Walker, Avian Research Program, Colorado Division of Parks and Wildlife, 711 Independent Ave., Grand Junction, CO 81505, USA.

\section{References Cited}

Aldridge, C.L., Saher, D.J., Childers, T.M., Stahlnecker, K.E., and Bowen Z.H., 2012, Crucial nesting habitat for Gunnison sage-grouse - A spatially explicit hierarchical approach - The Journal of Wildlife Management, v. 76, no. 2, p. 391-406.

Boyce, M.S., and Waller, J., 2000, The application of resource selection functions analysis to estimate the number of grizzly bears that could be supported by habitats in the Bitterroot ecosystem, in Servheen, C., ed., Grizzly bear recovery in the Bitterroot Ecosystem-Final environmental impact statement, Appendix 21B: U.S. Fish \& Wildlife Service, Missoula, Mont., p. 6-231-6-241.

Christiansen, T., 2000, Sage grouse in Wyoming-What happened to all the sage grouse?: Cheyenne, Wyo., Wyoming Wildlife News, v. 9, no. 5, Wyoming Game and Fish Department.

Connelly, J.W., and Braun, E.C., 1997, Long-term changes in sage grouse Centrocercus urophasianus populations in western North America: Wildlife Biology, v. 3, no. 3/4, p. 229-234. 
Connelly, J.W., Hagen, C.A., and Schroder, M.A., 2011, Characteristics and dynamics of Greater Sage-Grouse populations, in Knick, S.T., and Connelly, J.W., eds, Greater Sagegrouse-Ecology and conservation of a landscape species and its habitats: Berkeley, Calif., University of California Press, Studies in Avian Biology, v. 38, p. 53-67.

Connelly, J.W., Knick, S.T., Schroeder, M.A., Stiver, S.J., 2004, Conservation assessment of Greater Sage-grouse and sagebrush habitats: Cheyenne, Wyo., Western Association of Fish and Wildlife Agencies, unpublished report, 610 p.

Connelly, J.W., Schroeder, M.A., Sands, A.R. and Braun, C.E., 2000, Guidelines to manage sage grouse populations and their habitats: Wildlife Society Bulletin, v. 28, p. 967-985.

DeCesare, N.J., Hebblewhite, M., Schmiegelow, F., Hervieux, D., McDermid, G.J., Neufeld, L., Bradley, M. Whittington, J., Smith, K.G., Morgantini, L.E., Wheatley, M., and Musiani, M., 2012, Transcending scale dependence in identifying habitat with resource selection functions: Ecological Applications, v. 22, no. 4, p. 1,068-1,083.

Doherty, K.E., Naugle, D.E., Walker, B.L., and Graham, J.M., 2008, Greater sage-grouse winter habitat selection and energy development: Journal of Wildlife Management, v. 72 , p. $187-195$.

Fedy, B.C., Aldridge, C.L., Doherty, K.E., O’Donnell, M.O., Beck, J.L., Bedrosian, B.M., Holloran, J., Johnson, G.D., Kaczor, N.W., Kirol, C.P., Mandich, C., Marshall, A.D., McKee, G., Olson, C., Swanson, C.C., and Walker, B.L., 2012, Interseasonal movements of greater Sage-grouse, migratory behavior, and an assessment of the core regions concept in Wyoming: Journal of Wildlife Management, v. 76 , p. $1,062-1,071$.

Fedy, B.C., Doherty, K.E., Aldridge, C.E., O’Donnell, M.S., Beck, J.L., Bedrosian, B., Gummer, D., Holloran, M., Johnson, G., Kaczor, N., Kirol, C., Mandich, C., Marshall, D., McKee, G., Olson, C., Swanson, C., and Walker, B., 2014, Habitat prioritization across large landscapes, multiple seasons, and novel areas-An example using Greater Sage-Grouse in Wyoming: Wildlife Monographs, v. 190, p. 1-39.

Garton, E.O., Connelly, J.W., Horne, J.S., Hagen, C., Moser, A., and Schroeder, M.A., 2011, Greater Sage-Grouse population dynamics and probability of persistence: Studies in Avian Biology, v. 38, p. 293-382.

Hirzel, A.H., and Arlettaz, R., 2003, Modeling habitat suitability for complex species distributions by environmentaldistance geometric mean: Environmental Management, v. 32 , p. 614-623.

Hirzel, A.H., Le Lay, G. Helfer, V., Randin, C., and Guisan A., 2006, Evaluating the ability of habitat suitability models to predict species presences: Ecological Modelling, v. 199, p. $142-152$.
Holloran, M.J., and Anderson, S.H., 2005, Spatial disturbance of Greater Sage-grouse nests in relatively contiguous sagebrush habitats: The Condor, v. 107, p. 742-752.

Homer, C.G., Aldridge, C., Meyer, D.K., and Schell, S., 2012, Multi-scale remote sensing sagebrush characterization with regression trees over Wyoming, USA — Laying a foundation for monitoring: International Journal of Applied Earth Observation and Geoinformation, v. 14, p. 233-244.

Jiguet, Frederic, Arroyo, B., Bretagnolle, V., 2000, Lek mating systems-A case study in the Little Bustard (Tetrax tetrax): Behavioural Processes, v. 51, p. 63-82.

Manly, B.F.J., McDonald, L.L., Thomas, D.L., McDonald, T.L., and Erickson, W.P., 2002, Resource Selection by Animals-Statistical design and analysis for field studies (2d ed): Dordecht, The Netherlands, Kluwer Academic Publishers.

O’Donnell, M.S., Fancher, T.S., Freeman, A.T., Ziegler, A.E., Bowen, Z.H., and Aldridge, C.L., 2014, Large scale Wyoming transportation data-A resource planning tool: U.S. Geological Survey Data Series 821, 21 p., http://dx.doi.org/10.3133/ds821.

Sappington, J.M., Longshore, K.M., and Thompson, D.B., 2007, Quantifying Landscape Ruggedness for Animal Habitat Analysis - A Case Study Using Bighorn Sheep in the Mojave Desert: Journal of Wildlife Management, v. 71, no. 5 , p. 1419-1426.

Shepherd, J.F., Connelly, J.W., and Reese, K.P., 2011, Modeling nest and brood habitats of Greater Sage-grouse, chap. 10 of Sandercock, B.K., Martin, K., and Segelbacher, G., Ecology, conservation, and management of grouse-Studies in Avian Biology. Berkeley, Calif.: University of California Press, p. 137-150.

StataCorp, 2007, Stata statistical software-Release 10: College Station, Tex., StataCorp LP.

Stiver, S.J., Rinkes, E.T., and Naugle D.E., 2010, Sagegrouse habitat assessment framework: U.S. Bureau of Land Management Idaho State Office, Boise, Idaho, unpublished report.

Stiver, S.J., Apa, A.D., Bohne, J., Bunnell, S.D., Deibert, P.A., Gardner, S.C., Hilliard, M.A., McCarthy, C.W., and Schroeder, M.A., 2006, Greater Sage-grouse comprehensive conservation strategy, Western Association of Fish and Wildlife Agencies unpublished report: Cheyenne, Wyo. Western Association of Fish and Wildlife Agencies (WAFWA).

U.S. Fish and Wildlife Service, 2010, Endangered and threatened wildlife and plants-12-month findings for petitions to list the greater sage-grouse (Centrocercus urophasianus) as threatened or endangered: Federal Register 75, p. $13,909-14,014$. 
Publishing support provided by:

Denver Publishing Service Center, Denver, Colorado

For more information concerning this publication, contact:

Center Director, USGS Fort Collins Science Center

2150 Centre Ave., Bldg. C

Fort Collins, CO 80526-8118

(970) 226-9398

Or visit the Fort Collins Science Center Web site at: http://www.fort.usgs.gov/

This publication is available online at: http://dx.doi.org/10.3133/ds891 

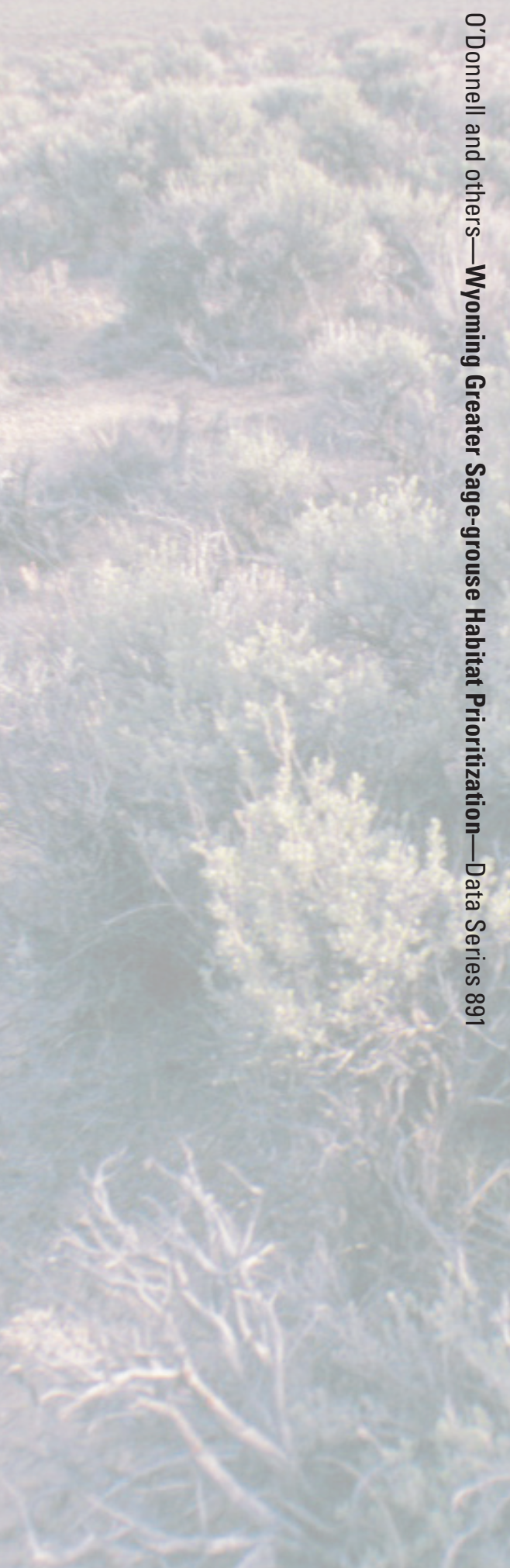